\title{
Experimental study on a precast beam-column joint with double grouted splice sleeves
}

Zhiwei Lu ${ }^{\mathrm{a}}$, Jun Huang ${ }^{\mathrm{a}, *}$, Shaobin Dai ${ }^{\mathrm{a}}$, Jixiong Liu ${ }^{\mathrm{a}}$, Mingzhong Zhang ${ }^{\mathrm{b}, *}$

${ }^{a}$ School of Civil Engineering and Architecture, Wuhan University of Technology, Wuhan 430070,

\section{China}

${ }^{b}$ Department of Civil, Environmental and Geomatic Engineering, University College London, London WC1E 6BT, UK

\begin{abstract}
The construction speed and quality of precast frame structures are greatly influenced by weld, tie, prestress, cast concrete requirements, etc. on site. To address these challenges, a precast beam-column joint connected by double grouted sleeves is proposed. This paper presents an investigation on seismic behaviour of the joint subjected to static and cyclic loadings. In total, six precast specimens with different assembly lengths, transition bar diameters and types of grouted sleeve and one cast-in-place control specimen were tested. Results show that the double grouted sleeve splices in joints perform well. The initial stiffness of prefabricated specimens is larger than that of the control specimen and the load bearing capacity of the prefabricated specimens is similar to that of the control specimen. As the transition rebar diameter increases from $16 \mathrm{~mm}$ to $18 \mathrm{~mm}$, the energy dissipation ability of the prefabricated specimens is increased by $64.8 \%$ but is approximately $41 \%$ lower than that of the control specimen due to their relatively lower deformation capacity. Threads in the grouted sleeve have a negative impact on the deformation and energy dissipation abilities of the joints. The method for cast-in-situ joint is adequate for predicting the flexural capacity of precast joint connected by double grouted sleeves.
\end{abstract}

Keywords: Precast concrete structures; Connections; Grouted sleeve; Cyclic loading; Plastic hinge

\section{Introduction}

Construction with the precast concrete method has gathered much attention as a substitution for conventional cast-in-situ concrete structures because of its good quality, cost effectiveness, accelerated construction speed and lower energy consumption [1-4]. Precast concrete frame structures are considered as one kind of promising precast concrete structure systems particularly suitable for the precast industry owing to their advantages including the convenience of prefabrication, standardization and erection [5]. However, the complexity and efficiency of connecting longitudinal reinforcement between precast beams and columns may impede widespread use of precast concrete frame structures. In recent decades, an increasing number of efforts have been made to solve the connection problems in precast concrete frame structures.

With respect to welded connections, Ersoy et al. [6] investigated the mechanical behaviour of precast beams with dry joints connected by welded steel plate under cyclic loading. They found that side steel plates are important for these joints to resist seismic action and the bearing capacity of elements without side plates was reduced obviously. Korkmaz et al. [7] developed a precast connection that is expected to be utilized in earthquake zones and suggested that one should be very careful with the welding quality of the steel to avoid premature failure near welding zones. Besides, Xiao et al. [8] explored a beam-column joint connected through welding the reinforcing bars at both ends of the precast beam and the protruding beam of the prefabricated column. They observed that the crack propagation and failure model of the prefabricated specimens were similar to those of the reference specimens. However, for the connections through welding, it is not easy to weld and guarantee the welding quality due to tight tolerances [6]. Additionally, special care is essential for

\footnotetext{
*Corresponding authors. E-mail addresses: hj@whut.edu.cn (J. Huang); mingzhong.zhang@ucl.ac.uk (M.
} Zhang). 
welding the longitudinal reinforcement and the welding process should be performed by experts, which may lead to an increase in labour costs.

Regarding bolted connections, Li et al. [9] conducted an experimental and analytical study of hybrid steel precast concrete connections and concluded that the steel sections in the connection significantly improved the strength of the connection core. However, joints with inadequate angle thickness and size were subjected to untimely failure at the joint zones with deformation of the angle sections. Choi et al. [10] tested four precast hybrid precast connections through steel couplers composed of bolting steel plates and steel tubes that were placed in the prefabricated beam and column. The typical flexural failure mode was found for all samples. The hybrid precast beam-column joints were developed by Ghayeb et al. [11], who observed that concrete did not crush in the precast specimens, whereas pinching occurred at a drift of $4.5 \%$. Besides, using angle steel and high strength steel studs significantly enhanced yielding capacity of the joints. Bahrami et al. [12] numerically studied the behaviour of two beam to column joints connected by embedded steel corbel with bolting and welding under lateral loading. The simulation results indicated that the stiffness and ductility of the precast connections were lower than those of cast-in-situ connection. In addition, Li et al. [13] and Nzabonimpa et al. [14] explored the seismic performance of joints with end-plates and concluded that the proposed joints with steel plates exhibited sufficient structural ability. Note that the bolted and hybrid connections may lead to steel congestion problems and need very compact tolerances in producing precast concrete members, which could be still a great impediment to many precast manufactures [15].

Regarding steel bar lapping splice connections, Parastesh et al. [16] proposed a ductile beam to column connection to enhance the seismic behaviour of precast frames. The continuity of longitudinal reinforcement of beams was achieved by lapped splice of steel bars at the end of the precast beam. Guan et al. [17] experimentally investigated a kind of beam to column joint consisting of concrete beams with a U-shaped section in the joint region. It was found that the main damage of the precast specimens occurred in the plastic hinge area and there was no need to make a short debonded length of the reinforcing bars in precast beams. Similarly, Lu et al. [18] reported the test results of a type of prefabricated beam to column joint with U-shaped rebar and engineered cementitious composites. However, it should be noted that the steel bar lapping splice in the precast joints often results in rebar congestion problems [19,20] and complicated construction of the connection core area with steel bar tying and concrete casting [4], which significantly increase the installation time and construction costs.

Regarding prestressed connections, Priestley and Tao [21] discussed the concept of connecting prefabricated concrete members by using beam prestressing tendons debonded through the connection. In the precast seismic structural systems (PRESSS) program, the pre-tension and post-tension connections were proposed and tested under pseudo-dynamic loadings [22,23]. It was reported that all the joint types were basically suitable for seismic design. Ozden and Ertas [24] investigated the effect of mild-steel ratio on structural performance of post-tensioned prefabricated joints and suggested a range of 20-30\% mild steel reinforcement. Alver et al. [25] explored the influence of short cantilever beam in prefabricated post tensioned joints on mechanical performance of the structure and found that the connections with a short cantilever beam can provide high displacement values and withstand severe deformation. Kaya and Arslan [26] tested the prestressed beam-column connections with corbels and estimated the influences of prestressed strand diameters on the behaviour of the connections. The connections with corbels would affect the appearance of 
the structures. Recently, Wang et al. [27] proposed a new precast prestressed frame joint and concluded that the post-tensioned strands can effectively offer a self-centring ability to the connections. However, the use of energy dissipation devices is needed to enhance the ability of prefabricated beam to column joints using post-tensioning to dissipate energy due to their low inherent damping [28]. Although different types of energy dissipation damping devices including steel yielding devices [22,29], friction damping devices [30-32] and lead extrusion damping devices $[33,34]$ have been experimentally validated through beam-column connection tests. For these joints using prestressing technology, the cost is considerably higher than a comparable cast-in-situ concrete structure [35] and the construction procedure of the precast prestressed connections is very complex [4].

As to dowel pin connections, the basic mechanical performance of them has been recently studied [36-39]. However, this type of connection is generally used in single-storey industrial buildings in Europe due to its distinctive structural behaviour.

To address the above-mentioned limitations of existing precast beam to column connections, a new prefabricated beam-column connection using double grouted sleeves is proposed in this study, as shown in Fig. 1. The major benefits of the proposed joint in comparison to the existing precast joints include rapid installation and saving cost, which are mainly resulted from eliminating welding, tying, prestressing and casting concrete requirements on site. Moreover, the grouted sleeves have adequate capacity to connect two disconnected steel bars [40-46].

This paper, for the first time, investigated the seismic performance of precast beam-column joints connected by double grouted sleeves through a series of tests. The effects of grouted sleeve type, assembly length of the connection, and diameter of transition bar on seismic performance of the joints were analysed and discussed. In addition, a comparison between the theoretical previsions of the flexural performance of the tested joints calculated according to the method for cast-in-situ beam-column joint and experimental data for precast joints was carried out to estimate whether the method for cast-in-situ beam-column joint is adequate for predicting the flexural ability of the precast beam to column connections connected by double grouted sleeves.

\section{Experimental program}

The proposed precast beam-to-column connection is composed of two grouted sleeves on a longitudinal bar, the behaviour of which could be different from the column foundation connections with single grouted sleeve on a steel bar presented in [1,47-50]. Besides, the testing method for the column foundation joint is different from that for beam-column joint due to different connection types and investigation objectives. Thus, a new experimental program should be conducted for the proposed precast joint to evaluate its seismic performance.

\subsection{Test specimens}

In total, seven beam-column connections were designed and tested: six prefabricated concrete beam to column joints and one cast-in-situ concrete beam-column joint. For each joint, the column had a cross-section of $350 \mathrm{~mm} \times 350 \mathrm{~mm}$ and a total height of $2000 \mathrm{~mm}$ and the beam had a cross-section of $200 \mathrm{~mm} \times 350 \mathrm{~mm}$ and a total length of $1500 \mathrm{~mm}$. The longitudinal steel reinforcement of all columns was composed of $4 \Phi 16 \mathrm{~mm}$ both along the sides of the column section and in the middle of the sides. The longitudinal steel reinforcement of all beams consisted of $2 \Phi 16 \mathrm{~mm}$ both in the upper and lower parts. The transverse steel bar was provided with rectangular stirrup $\Phi 8 \mathrm{~mm} @ 100 \mathrm{~mm}$, while the space of stirrup was less than $100 \mathrm{~mm}$ in the local region of beam for precast specimens. Fig. 2 shows the reinforcement details and dimensions 
of the tested specimens.

Since all types of grouted sleeve are not available in the market for the long grouted sleeves and the commercial sleeves are expensive due to the use of high-strength materials and the complex manufacturing processes, two low-cost grouted sleeves, i.e. grouted sleeve with wedge (GSW) and grouted sleeve with wedge and thread (GSWT) previously developed by the authors [51] were used in this study (see Fig. 3). Fig. 4 and Table 1 show the dimensions of GSW and GSWT that were made of the low alloy seamless steel tubes with specified yield strength of $390 \mathrm{MPa}$. The thickest and thinnest parts of the wedge are $4 \mathrm{~mm}$ and $1 \mathrm{~mm}$, respectively. The difference between the two types of grouted sleeve is that GSWT has small threads in the sleeve (see Figs. $3 \mathrm{~b}$ and 4b). For labels GW-1 and GT-1, "GW" and "GT" represent GSW and GSWT respectively, and "1" denotes the sleeve number.

An experiment was firstly conducted to study the mechanical behaviour of the grouted sleeve splices (GSW and GSWT) under monotonic tensile loading (the spliced bar diameter is $16 \mathrm{~mm}$ ). The test results show that all the grouted sleeve splice samples suffered bar fracture outside the sleeves (see Fig. 5), which indicates that GSW and GSWT can effectively splice two discontinue steel bars.

The main test variables in this work were the type of grouted sleeve, assembly length of the connection and diameter of the transition bars. Two types of grouted sleeve including GSW and GSWT, two types of assembly length including $0 \mathrm{~mm}$ and $425 \mathrm{~mm}$, and two transition bar diameters of $16 \mathrm{~mm}$ and $18 \mathrm{~mm}$ were investigated. The assembly length of the connection (i.e. the length of the protruding beam of the precast column) is the distance between the surface of column and the junction surface between precast beam and column. The specimen design details are summarized in Table 2.

\subsection{Materials}

Table 3 illustrates the mechanical properties of steel reinforcement (type HRB 400) utilized in this work including tensile strength, yield strength and elastic modulus. Concrete cubes of $150 \mathrm{~mm} \times$ $150 \mathrm{~mm} \times 150 \mathrm{~mm}$ were prepared and tested after a standard curing for 28 days to acquire the compressive strength of concrete. The compressive and flexural strengths of the grout and filler were tested on prism specimens with size of $40 \mathrm{~mm} \times 40 \mathrm{~mm} \times 160 \mathrm{~mm}$ in accordance with JG/T408 [52]. The flexural tests were firstly conducted on prism specimens followed by the compression tests on the broken prisms according to GB/T17671 [53]. The mechanical properties of concrete, grout and filler are listed in Table 4.

\subsection{Specimen preparation}

The precast members (columns and beams) and the cast-in-situ specimen were cast simultaneously in wooden formwork. The reinforcing cage and grouted sleeves were put together and placed inside the wooden formwork beforehand. Fig. 6 presents the production process of the precast specimen that consists of six main steps: (1) hoist prefabricated column using a crane; (2) lift prefabricated beam through a crane after putting transition bar into long grouted sleeve of precast beam; (3) adjust the prefabricated column and beam to design position (the connection distance between column and beam is $30 \mathrm{~mm}$ ); (4) move the transition bar from long grouted sleeve in precast beam to short grouted sleeve in precast column or in the protruding beam of precast column and keep the same length of transition bar in the long and short grouted sleeves; (5) prepare formwork for filler; (6) obtain the precast specimens after grouting the sleeves, pouring the filler, demoulding, whitewashing one face of the specimen and drawing the grid of $50 \mathrm{~mm} \times 50 \mathrm{~mm}$ in order to 
observe cracks easily. The assembly steps of the proposed connection in multi-storey assembled buildings are basically the same as these steps except that no whitewashing and gridding are required.

It should be mentioned that the estimated costs and the workload of the joint connected by double grouted splice sleeves may be increased. However, the joint can significantly improve the assembly speed and increase the speed of capital returns, which are in turn beneficial to the investor. Besides, in comparison with casting concrete and tie on site, the grouting workload is small and can be significantly reduced through the usage of pressure grouting machine.

\subsection{Test setup and loading}

In this experiment, vertical loads imposed at the beam free end were applied, as shown in Fig. 7. An actuator with $\pm 250 \mathrm{~mm}$ displacement range and $\pm 600 \mathrm{kN}$ load capacity was mounted vertically at beam free end to exert static and low-reversed cyclic loading. A jack with maximum ability of 3000 $\mathrm{kN}$ was placed on the top of column to acquire a constant axial compression force. The axial load on the top of column was maintained at $700 \mathrm{kN}$ throughout the test.

A two-part test procedure was conducted in the study: (1) the specimen of BCJ-S was firstly tested under static loading to acquire basic information (e.g. yield load and maximum load) of the proposed precast beam-column joints; (2) the remaining specimens including BCJ-1, BCJ-2, BCJ-3, BCJ-4, BCJ-5 and BCJ-C were then tested under low-reversed cyclic load to obtain the seismic behaviour of the proposed precast connections. The mixed loading protocols of load and displacement (see Fig. 8) were chosen in this experiment according to the seismic test guideline JGJ/T101-2015 [54]. Before the specimen yields, a load-control loading scheme was applied, and the loading circle was used only once for every loading step. After the specimen was yielded, the displacement-control was conducted and repeated three times at first three loading steps and all repeated two times after the third loading step.

Linear variable differential transformers (i.e. LVDTs) and strain gauges were utilized to obtain the strain of the reinforcement and the grouted sleeves in the specimens. The arrangement of the LVDTs and the strain gauges is presented in Figs. 9 and 10. During the test, load, strain and displacement were acquired and recorded automatically by a computer.

\section{Results and discussion}

\subsection{Monotonic loading test}

\subsubsection{Failure modes}

The failure of the precast beam-column connection (BCJ-S) under static loading is shown in Fig. 11. The grouted sleeves, the reinforcement and the concrete worked together to carry the load, at the early phase of loading. The first crack occurred at the fourth whitewashing grid of beam which was located outside the beam to column joint on the tensile side of the beam at a load of $13 \mathrm{kN}$. With the increase of load value, the existing cracks grew, and new cracks were observed in the scope of length equivalent to approximately the double beam height. These cracks propagated from vertical cracks to oblique cracks. When the applied load exceeded $40 \mathrm{kN}$, the stiffness declined significantly, which can be seen from the load-deflection curve presented in Fig. 12. Afterwards, the test was continued under displacement control with an increment of displacement of $5 \mathrm{~mm}$ per loading step. The cracks initiated and grew continuously due to the addition of vertical displacement imposed on the beam end. The maximum crack width located at the interface of beam and column at a displacement of $26 \mathrm{~mm}$ corresponding to the load of around $43.2 \mathrm{kN}$ was approximately $2 \mathrm{~mm}$. The longitudinal splitting crack near the interface of beam-column was observed at a displacement value 
of $35 \mathrm{~mm}$ corresponding to a load of around $43.9 \mathrm{kN}$. Finally, concrete at the beam end near the column on the compression face crushed and the utmost crack width was around $6 \mathrm{~mm}$, which indicated the final failure of the specimen (Fig. 11c). It should be mentioned that there was no crack observed at the core zone of beam to column joint and no damage caused by bond failure between longitudinal bars and grout in the grouted sleeve connectors was found (Fig. 11d).

\subsubsection{Load-displacement response}

Fig. 12 depicts the load-displacement curve for the specimen of BCJ-S illustrated in Fig. 2b. The specimen BCJ-S yielded when the load was $37.19 \mathrm{kN}$ and the corresponding vertical displacement was $9.33 \mathrm{~mm}$. As seen in Fig. 12, before the yield point, the specimen BCJ-S showed a bilinear characteristic commencing from a linear elastic zone followed by another linear elastic zone with a lower stiffness. This may be attributed to the micro cracks of grout developed in the grouted sleeves or other reasons that could not be observed by eyes. The initial stiffness (i.e. the slope of the first segment of the load-displacement curve before yielding) of BCJ-S was $4.96 \mathrm{kN} / \mathrm{mm}$, while the following stiffness of the specimen dropped a little bit until the yielding of the specimen, which equals to around $4.09 \mathrm{kN} / \mathrm{mm}$. After yielding, the stiffness of the sample decreased obviously, and the load of the sample increased gradually with the growth of flexural cracks up to the maximum load of $44.6 \mathrm{kN}$ corresponding to the displacement of $47.89 \mathrm{~mm}$. However, after reaching the level of the maximum load, the load carrying ability of the sample decreased slowly with increasing displacement. This indicates that the specimen BCJ-S exhibited a ductile failure mode and had a good deformation capacity under static loading.

\subsubsection{Load-strain response}

It can be observed that the strain was very small indicating that the deformation and stress in the beam-column core region were small and the core region was very strong. This result can be ascribed to the larger section area of the column than the beam and is consistent with the failure mode shown in Fig 11d.

The measured strain of reinforcement in the beam of the specimen BCJ-S was presented in Fig. 14. The load-strain response of the steel bar in the short-grouted sleeve (SGS) end showed the same tendency that the strain increased as the load increased gradually. The maximum strain of the longitudinal rebar in the SGS end on the face of tension was observed to be $5521 \mu \varepsilon$ at failure, which is much bigger than the yield strain $(2162 \mu \varepsilon)$ of the steel bar and the strain values in the SGS end on the compression region face (Fig. 14a). The overall load-strain behaviour of the longitudinal rebar in the long-grouted sleeve (LGS) end was similar to that of rebar in the SGS end. The strain values in the LGS end on both faces of tension and compression were lower than that in the SGS end due to the lower bending moment in the LGS end. The maximum longitudinal strain of the rebar in the LGS end was equal to $951 \mu \varepsilon$, which is smaller than the yield strain of reinforcement (Fig. 14a). As illustrated in Fig. 14b, the strain of the stirrups perpendicular to the main reinforcement of the beam was rather small in the load-control stage. However, in the displacement-controlled phase, the strain of stirrups in the SGS end increased sharply throughout the displacement loading phase and the maximum value was $1350 \mu \varepsilon$. This result can be attributed to the inclined crack in the SGS end that propagated and became quickly wider in the displacement-controlled stage, leading to a sharp increase in the force in the stirrup (Fig. 11a).

Figs. 15 and 16 show the load-strain development of the grouted sleeves in specimen BCJ-S. It can be seen from Fig. 15a that the load-strain response of the SGS on the tensile face of the beam showed a same tendency that the strain increased as the load increases, and the longitudinal strain 
was tension strain, while the circumferential strain was compression strain until the yield load, which can be attributed to the Poisson's effect. However, the longitudinal strain of strain gauge S1 was inclined to be compression strain and the circumferential strain of strain gauge $\mathrm{S} 2$ changed into tension strain after the specimen BCJ-S yielded. This can be ascribed to the splitting cracks that were developed around the rebar under the circumstance of high tension load leading to expansion of the sleeve. Subsequently, after the steel rebar yielded (referring to strain gauge B1), the longitudinal strain of strain gauge S1 became compression strain and the circumferential strain of measure point $\mathrm{S} 2$ became tensile strain at the end of the test, which reflected the active confinement effect of the sleeve. It can be found from Fig. 15b that the load-strain response of the SGS on the compression face of the beam exhibited a tendency that the strain increased with increasing load and the longitudinal strain was compressive, while the circumferential strain was tensile until the maximum load, which seems to be in contrast to the load-strain response of the grouted sleeve on the tension face. The LGS on the faces of tension and compression of the beam exhibited a similar strain development as compared to the SGS (Fig. 16). The strain gauge L4 was broken. In comparison with the SGS on the tension face of the beam, the LGS was under a lower tensile force and thus the longitudinal strain and transverse strain did not tend to change from tension to compression. Due to the large diameter and thick wall of the grouted sleeves, all the grouted sleeves in specimen BCJ-S did not yield (the yield strain of the grouted sleeve was $1893 \mu \varepsilon$ ).

3.2 Cyclic loading test

\subsubsection{Failure modes}

Fig. 17a shows the damage observed for the control specimen BCJ-C. Four flexural cracks started at the lower part of the beam at a pulling load of $-8 \mathrm{kN}$, while one vertical crack was induced at the upper corner of the joint at a load of $12 \mathrm{kN}$. When the load increased, new cracks appeared, and the existing cracks propagated in the beam. Nonlinear characteristic was observed on the load-displacement curve (Fig. 18a) as the pushing load was $28 \mathrm{kN}$ corresponding to a displacement of $7.93 \mathrm{~mm}$, which implies that the specimen entered the inelastic stage [55]. Subsequently, displacement-control was initiated and the displacement increment $(\Delta)$ was $7.93 \mathrm{~mm}$. It is worth mentioning that four main cracks at the first, third, seventh and tenth grid of the beam crossed the whole beam section at this time. The maximum load of $46.18 \mathrm{kN}$ was reached when the loading displacement was $2 \Delta$. Inclined shear cracks were induced in the scope of $150 \mathrm{~mm}$ at the beam end near the column at a loading displacement of $3 \Delta$. At last $(11 \Delta)$, this specimen failed with concrete crushing at the beam-end over a length of about $150 \mathrm{~mm}$ due to compression damage of the concrete, which resulted in a sudden drop of load. Additionally, no crack was found in the column.

For the specimen BCJ-1, fine hairline cracks were first observed at the interface of the precast beam and the filler in the bottom of the beam as the load reached $-4 \mathrm{kN}$. The first crack propagated and crossed the whole beam section at load value of $16 \mathrm{kN}$. The second flexural crack in the bottom of the beam at approximately $400 \mathrm{~mm}$ from the beam end appeared at a load value of $-20 \mathrm{kN}$. When the loading displacement was $2 \Delta(\Delta=4.50 \mathrm{~mm})$, four new vertical cracks were found in the top of the beam and the spacing was approximately $150 \mathrm{~mm}$. Two oblique cracks formed in the filler during the second loading cycle at a loading displacement of $3 \Delta$. The filler in the bottom of the beam started spalling and the specimen reached its maximum bearing capacity of $51.31 \mathrm{kN}$ corresponding to the displacement of $7 \Delta$. Finally, the cracks in the beam end became wider and the spalling of the filler was severe (Fig. 17b).

The overall performance of the specimens BCJ-2 and BCJ-3 was similar with that of the sample 
BCJ-1, as illustrated in Fig. 17c and d. The initial cracks were noticed on the specimens BCJ-2 and $\mathrm{BCJ}-3$ at load value of $12 \mathrm{kN}$ and $16 \mathrm{kN}$ respectively, which were higher than that for the specimen BCJ-1. Regarding the specimens BCJ-2 and BCJ-3, the maximum load was found to be $-50.50 \mathrm{kN}$ and $57.63 \mathrm{kN}$ corresponding to the displacement of $7 \Delta(\Delta=5.75 \mathrm{~mm})$ and $8 \Delta(\Delta=5.81 \mathrm{~mm})$ respectively when the filler was crushed. For the specimen BCJ-3, more cracks existed in the beam compared to the specimens BCJ-1 and BCJ-2, which can be attributed to the large diameter of the transition bar used in the specimen BCJ-3.

Fig. 17e shows the final failure mode of the specimen BCJ-4. Two minor hairline cracks developed at the beam to column interface and at the interface of the precast beam and the filler, respectively, at a load of $-8 \mathrm{kN}$. A major hairline crack crossed the interface between the precast beam and the filler at a load value of $16 \mathrm{kN}$. The cracks spread and new cracks developed slowly in the load-controlled stage, while cracks developed quickly in the displacement-controlled stage. The existing cracks propagated from vertical flexural cracks to inclined shear cracks as the load increased. The maximum load of $-47.33 \mathrm{kN}$ was reached at a displacement of $6 \Delta(\Delta=8.27 \mathrm{~mm})$. In the first loop of $8 \Delta$ displacement loadings, the rebar in the bottom of the beam end could be observed, and the concrete fractured severely in the beam end in the range of approximately 150 $\mathrm{mm}$. The test was then stopped.

The behaviour of the specimen BCJ-5 was very similar with that of the specimen BCJ-4, as shown in Fig. 17f. At a load of $12 \mathrm{kN}$, two vertical cracks were observed in the top of beam end, and the spacing between the two cracks was approximately $200 \mathrm{~mm}$. The third crack was also found at load value of $12 \mathrm{kN}$ at the precast beam-filler interface. A main micro-crack crossed the whole section of the beam end when the load reached $20 \mathrm{kN}$. Another micro-crack crossed the interface between the precast beam and the filler at load value of $-24 \mathrm{kN}$ followed by a new crack developed at about $200 \mathrm{~mm}$ away from the beam end when the loading displacement reached $-\Delta(\Delta=$ $6.23 \mathrm{~mm}$ ). When the loading displacement increased, the cracks grew further and the maximum load of $-46.57 \mathrm{kN}$ was reached at a displacement of $6 \Delta$. At the second cycle of $9 \Delta$, the concrete in the beam end spalled severely and the load dropped significantly. The testing of BCJ-5 was then terminated.

In general, the failure modes of the precast specimens BCJ-1, BCJ-2, BCJ-3, BCJ-4 and BCJ-5 were different from those of the cast-in-place specimen BCJ-C. The damage was not severe, and the plastic hinge length was shorter for the specimens BCJ-1, BCJ-2 and BCJ-3 compared to the specimen BCJ-C, which can be attributed to the four long grouted sleeves embedded in the precast beam [48] (Figs. 17b-d and 2). These grouted sleeves led to an enhancement in the local strength of the beam end, which helped to resist the damage of the beam. Similar findings can be found in $[47,50]$. Consequently, the damage of the specimen concentrated on the fracture and spalling of the filler rather than the concrete. Unlike other specimens, the specimens BCJ-4 and BCJ-5 had a longer plastic hinge length in comparison with specimens BCJ-1, BCJ-2, and BCJ-3, and exhibited different failure modes, indicating that the failure mode is dependent on the connection type. The cracks were distributed over a length of approximately $1000 \mathrm{~mm}$ on the beam for the specimens BCJ-C, BCJ-1, BCJ-2 and BCJ-3, while the cracks of the specimens BCJ-4 and BCJ-5 were only distributed over a length of approximately $550 \mathrm{~mm}$. This difference can be interpreted by the fact that the long grouted sleeves helped to restrain the cracking of the precast beam of the specimens BCJ-4 and BCJ-5 in the region next to the filler, where the bending moment was lower than in the short sleeve region. Based on the obtained crack loads of the specimens BCJ-1, BCJ-2, BCJ-4 and 
BCJ-5, it can be found that threads in sleeve had less influence on the crack loads of the proposed precast connections because of the similar work performance of GSW and GSWT in the case of small load. It should be mentioned that no cracks were observed in the column and no damage was found in the grouted sleeve connectors for all precast specimens. As a result, the precast specimens met the goal of having a strong column, a weak beam, and a stronger joint.

\subsubsection{Hysteretic response}

The load-deflection hysteresis curves can directly indicate the seismic capacity of the connections, which are usually utilized to investigate the seismic behaviour of the structures [56,57]. Fig. 18 shows the six load-deflection hysteretic curves of the samples BCJ-C, BCJ-1, BCJ-2, BCJ-3, BCJ-4 and BCJ-5. All specimens, including the monolithic specimen and the precast specimens, exhibited a typical flexural behaviour from a seismic loading point of view with no significant pinching effect [58]. The hysteretic curves of all specimens roughly circulated along a straight line at the early stages of loading. Besides, residual deformation was almost absent after unloading and the hysteretic circle was very small. As the displacement increased, the specimens reached an elastic-plastic range and the stiffness of the specimens degraded, which indicated that the damage of the specimens was accumulated. Given that new cracks emerged, and existing cracks propagated in the second loop of loading even at the same loading level, the strength of the specimen was accordingly decreased. After the maximum load was reached, the load carrying capacity of the precast specimens did not decline very much with an increase of loading displacement, which indicates the good ductility of the precast specimens [59].

\subsubsection{Skeleton curves}

Fig. 19 illustrates the load-displacement skeleton curves of the samples under cyclic loading, where Fig. 19a plots the envelope from the first cycle of the push-pull loadings, while Fig. 19b reflects the average envelope from the same cycle of the push-pull loadings. The overall shape of the skeleton curves of the prefabricated specimens was similar with that of reference specimen. The initial stiffness up to a vertical load of $30 \mathrm{kN}$ was almost the same among the precast specimens BCJ-1, BCJ-2, BCJ-3, BCJ-4 and BCJ-5. After a load of $30 \mathrm{kN}$, the stiffness of the prefabricated specimens began to soften due to yielding. However, the stiffness of the control specimen of BCJ-C was smaller than that of the precast specimens, which indicates that the connection connected by double grouted sleeves would improve the stiffness of the precast frame structures significantly (see Fig. 19b).

The feature parameters including the yield load $\left(P_{y}\right)$ and corresponding displacement $\left(\Delta_{y}\right)$, maximum load, and corresponding displacement, as well as the failure load and corresponding displacement are summarized in Table 5. Herein, the yield points were directly defined when the first yield occurs in the specimens based on the skeleton curves of the specimens, as shown in Fig.

19a. For the specimen BCJ-C, the average yield load $\left(\overline{P_{y}}\right)$ was $43.12 \mathrm{kN}$, which is $3.8 \%, 0.5 \%, 0.6 \%$ and 5.4\% larger than that of the specimens BCJ-1, BCJ-2, BCJ-4 and BCJ-5, respectively. This shows that the average yield load of the precast specimens was close to that of the control specimen. In addition, the yield load was increased by $18.7 \%$ when the transition bar diameter of the specimen BCJ-3 was enhanced from $16 \mathrm{~mm}$ to $18 \mathrm{~mm}$.

The average maximum load $\left(\bar{P}_{\max }\right)$ of the specimen BCJ-C was $45.30 \mathrm{kN}$, which is $0.4 \%$ higher than that of the specimen BCJ-1, 0.1\% smaller than that of the specimen BCJ-2, $1.8 \%$ higher than that of the specimen BCJ-4 and 5.9\% higher than that of the specimen BCJ-5. This reflects that the bearing capacity of the specimens BCJ-1 and BCJ-2 was very close to that of the specimen BCJ-C, 
while the bearing capacity of the specimens BCJ-4 and BCJ-5 was lower than that of the specimen BCJ-C. Overall, the bearing ability of the prefabricated specimen spliced by the double grouted sleeve was similar to that of the reference specimen BCJ-C.

The specimens BCJ-1 and BCJ-2 achieved about 5.4\% and 2.0\% greater average maximum load carrying capacity than the specimens BCJ-5 and BCJ-4, respectively, as listed in Table 5. This can be attributed to the higher compressive strength of the filler in the beam end of the specimens BCJ-1 and BCJ-2 compared to the concrete strength in the beam end of the specimens BCJ-4 and BCJ-5. In addition, it can be found that the maximum load of the specimen BCJ-3 is $20.4 \%$ larger than that of the specimen BCJ-1. The reason for this is that the transition bar in the specimens BCJ-1 and BCJ-3 was located in the cross section with maximum bending moment and the strength of the long grouted sleeves is greater than that of the transition bar, which indicates that the bearing capacity of the precast joint with no protruding beam in the precast column is controlled by the transition bar diameter and the compressive strength of the filler. When the diameter of the transition bar is increased, the capacity of the joint to resist the maximum bending moment can be improved significantly. Consequently, increasing the diameter of the transition bar in the precast specimens with no protruding beam in the precast column is a good solution to improve the load bearing capacity evidently due to the short length of the transition bar and a low cost. However, the load bearing capacity of the precast connection with protruding beam (e.g. BCJ-4 and BCJ-5) is only affected by the longitudinal bar diameter in the short sleeve end and the compressive strength of concrete. This implies that increasing the diameter of the transition bar has no effect on the load bearing capacity of the precast joint with protruding beam in the precast column.

3.2.4 Displacement ductility and deformation capacity

The displacement ductility ratio $\left(\mu_{\Delta}\right)$, developed in the Chinese code for seismic buildings [54], is defined as the coefficient of failure displacement $\left(\Delta_{u}\right)$ to yield displacement $\left(\Delta_{y}\right)$, expressed by:

$\mu_{\Delta}=\frac{\Delta_{u}}{\Delta_{y}}$

The ductility coefficients obtained from Eq. (1) for the specimens under cyclic loading are listed in Table 5, and the average ductility coefficients $(\bar{\mu})$ were calculated to compare the ductility level of the specimens. The average ductility coefficient of the specimen BCJ-C is $5.2 \%$ and $4.4 \%$ higher than that of the specimens BCJ-1 and BCJ-2, respectively. However, the average ductility ratio of the specimen BCJ-C is $17.6 \%$ and $1.3 \%$ lower than that of the specimens BCJ-4 and BCJ-5, respectively, which is a result of the lower yield displacement of the precast specimens compared to the control specimen. This suggests that the precast specimens had excellent ductility. The average ductility ratio of the specimen BCJ-3 is the same as that of the specimen BCJ-1, which indicates that increasing the diameter of transition bar would have no influence on the ductility of the precast specimens.

It can be found in Table 5 that the average ductility ratio of the specimens BCJ-4 and BCJ-5 is $26.6 \%$ and $6.6 \%$ higher than that of the samples BCJ-2 and BCJ-1, respectively, implying that the location of the grouted sleeves in the beam has an influence on the ductility of the connection. In addition, the average ductility ratio of the specimens BCJ-2 and BCJ-4 is $0.8 \%$ and $19.7 \%$ higher than that of the samples BCJ-1 and BCJ-5 respectively, which implies that the ductility of the connection is influenced by the type of the grouted sleeve in the specimen and the joint connected by GSW has a better ductility than the joint connected by GSWT. It should be mentioned that the average coefficient of all the specimens under cyclic loading is larger than that of the reinforced 
concrete structures $\left(\mu_{\Delta} \geq 2\right)$ and the steel-concrete composite structures $\left(\mu_{\Delta} \geq 4\right)$ suggested in $[60,61]$.

As seen in Table 5, the failure displacement of specimen BCJ-C is $76.0 \%, 53.4 \%, 36.6 \%, 19.8 \%$, and $41.3 \%$ larger than that of the precast specimens BCJ-1, BCJ-2, BCJ-3, BCJ-4, and BCJ-5, respectively. This indicates that the deformation ability of the precast joints proposed is lower than that of the cast-in-situ joint under cyclic loading. This is because the grouted sleeves decreased the local deformation capacity of the beam. The same finding is also presented in $[1,49]$. With the increase of the assembly length from $0 \mathrm{~mm}$ to $425 \mathrm{~mm}$, the failure displacement of specimens BCJ-4 and BCJ-5 is $28.0 \%$ and $24.5 \%$ higher than the specimens BCJ-2 and BCJ-1, respectively. This can be explained by the fact that the beam end with long grouted sleeves that had a larger stiffness than the beam end with only steel bars could reduce the deformation capacity of the specimens. The failure displacement of the samples of BCJ-4 and BCJ-2 is $18.0 \%$ and $14.8 \%$ higher than the specimens BCJ-5 and BCJ-1, respectively, which indicates that threads could improve the friction stress between the sleeve and the grout inside the sleeve could decrease the deformation ability of the joint. Besides, increasing the transition bar diameter could improve the deformation capacity significantly since the failure displacement of the specimen BCJ-3 is $28.9 \%$ larger than that of the specimen BCJ-1. However, since the transition rebar of the joint with protruding beam in the precast column (e.g. BCJ-4 and BCJ-5) is far from the plastic hinge zone, the increase of the diameter of the transition bar cannot improve the failure displacement.

\subsubsection{Dissipated energy}

In addition to the displacement ductility, the energy dissipation capacity is another important parameter, which is utilized to quantify the energy absorption capacity of structures in seismic design. The energy dissipation can reflect the load-carrying history and the maximum displacement reached, and the dissipated energy could be a significant efficiency parameter, independently from the displacement ductility [58]. The dissipated energy per cycle is computed from the area of the enclosed loop $A B C D A$ in every loading cycle (Fig. 20).

Fig. 21a shows the cumulative dissipated energy versus the vertical displacement of the precast and the control specimens. It can be found that before the vertical displacement reached around 45 $\mathrm{mm}$, almost all the precast specimens had a higher cumulative dissipated energy than the control specimen. Whereas after the vertical displacement was larger than approximately $55 \mathrm{~mm}$, the cumulative dissipated energy of the control specimen increased significantly and was beyond all the precast specimens at the end stage. This reflects that the energy dissipation capacity of the precast joints proposed in this study is better than cast-in-situ joints exposed to small earthquakes while the energy dissipation ability of cast-in-situ joints is better than the precast connections exposed to big earthquakes.

Fig. $21 \mathrm{~b}$ illustrates the ultimate cumulative dissipated energy at the end of the experiment. It can be found that the average ultimate cumulative dissipated energy of the prefabricated specimens was $41 \%$ smaller than that of the control specimen, which indicates that the overall behaviour of energy dissipation capacity of the proposed precast joints is lower than that of the reference joint. This situation can be mainly attributed to the fact that the grouted sleeves possess larger stiffness than regular steel bars resulting in a decrease of the deformation capacity of the precast specimen, which thus leads to the lower energy dissipation ability compared with the reference specimen. The ultimate cumulative dissipated energy of the specimens BCJ-4 and BCJ-5 is $22.8 \%$ and $33.2 \%$ higher than that of the specimens $\mathrm{BCJ}-2$ and $\mathrm{BCJ}-1$, respectively. This is because the plastic hinge 
length of the specimens BCJ-4 and BCJ-5 with an assembly length of $425 \mathrm{~mm}$ is longer than that of the specimens BCJ-2 and BCJ-1, which had an assembly length of $0 \mathrm{~mm}$. Thus, the assembly length has an impact on the energy dissipation ability of the specimens and the grouted sleeves far away from the column are beneficial to the energy dissipation of the joint. The ultimate cumulative dissipated energy of the specimens BCJ-2 and BCJ-4 is $10.4 \%$ and $1.8 \%$ larger than that of the specimens BCJ-1 and BCJ-5, respectively, which demonstrates that the configurations of the grouted sleeves have an obvious effect on the energy dissipation of the joint, and the energy dissipation ability of the connection spliced by GSW is better than that of the connection spliced by GSWT. Therefore, threads providing an interlocking mechanism in GSWT have a negative impact on the energy dissipation of the precast joints compared with GSW. Moreover, the ultimate cumulative dissipated energy of the specimen BCJ-3 is $64.8 \%$ larger than that of the specimen BCJ-1, which shows that increasing the transition bar diameter could obviously improve the energy dissipation ability of the connection. This is due to the load carrying capacity of the specimen BCJ-3 which was significantly improved as the transition bar diameter was increased, resulting in an increase of the area of the hysteresis loops. Consequently, increasing the diameter of the transition bar to enhance the energy dissipation of the prefabricated joint is an effective and economic measure due to the low cost of the transition bar. It should be noted that this conclusion applies only to the precast joint with no protruding beam but not to the joint with protruding beam in the precast column. As the transition rebar of the joint with protruding beam is far from the plastic hinge area, increasing the transition rebar diameter cannot increase the strength and deformation capacity of the joint. Thus, it can be predicted that the energy dissipation capacity of the precast connection with protruding beam would not be improved with the increase of the diameter of the transition rebar. In order to estimate the influences of the distance between the precast column and the precast beam and the compressive strength of the cast-in-situ filler on the energy dissipation of the precast joint, further experimental research should be conducted.

To further investigate the energy dissipation ability of the joints, the equivalent viscous damping ratio is used here. It can show the pinching degree of the hysteresis loop and will be altered for different loading cycles. As the pinching in the hysteresis loop becomes very obvious and the energy dissipation ability of the sample begins to decline, the equivalent viscous damping ratio $\left(h_{e}\right)$ defined as follows will decrease [62].

$h_{e}=\frac{S_{A B C D A}}{2 \pi\left(S_{O B F}+S_{O D E}\right)}$

where $S_{A B C D A}$ is the area of the enclosed loop ABCDA, $S_{O B F}$ and $S_{O D E}$ are the areas of the triangles $\mathrm{OBF}$ and $\mathrm{ODE}$, respectively (see Fig. 20).

Fig. 22 illustrates the relationships between $h_{e}$ and the loading step for the specimens under cyclic loading. $h_{e}$ of the specimen BCJ-2 decreased in the last two loading steps, which indicates that the pinching occurred in the hysteresis loop of the specimen BCJ-2. Whereas $h_{e}$ of the other specimens, i.e., BCJ-1, BCJ-3, BCJ-4, BCJ-5 and BCJ-C increased with the increase of loading step and did not reduce in the last several loading steps, which implies that the hysteresis loop of the rest specimens did not pinch.

\subsubsection{Strength degradation}

Increasing the loading cycles subjected to the same loading step would lead to a strength degradation (i.e. decrease of load carrying ability) of the specimen. In order to evaluate the strength degradation of the connections in this study, the strength degradation ratio $\left(\lambda_{i}\right)$ developed in the 
Chinese specification [54] was chosen. It can be calculated as follows:

$\lambda_{i}=\frac{F_{j}^{i}}{F_{j}^{i-1}}$

where $F_{j}^{i-1}$ and $F_{j}^{i}$ are the maximum load values of the $(i-1)$ th and $i$ th loading cycle respectively at the $j$ th loading step.

Fig 23 illustrates the strength reduction curves of the samples under cyclic loading in the second loading loop. It can be observed that the values of $\lambda_{i}$ of the specimens BCJ-1, BCJ-3, BCJ-4 and BCJ-5 ranged from 0.89 to 1 , which was similar to that of the specimen BCJ-C ranging from 0.90 to 0.99. The ratio $\lambda_{i}$ of the specimen BCJ-2 ranged from 0.89 to 0.99 except for the last loading step. Therefore, it is concluded that the strength degradation of the precast specimens, compared with the reference specimen, was not obvious when the precast specimens were in the second loading cycle. This indicates that the proposed precast connection has adequate load carrying capacity to resist the earthquake under the circumstance that the connections are in cyclic seismic action.

\subsubsection{Stiffness characteristics}

In order to evaluate the stiffness reduction level of the samples, the secant stiffness presented in [54] is utilized, which is calculated by:

$K_{\mathrm{i}, \mathrm{j}}=\frac{\left|+F_{i, j}\right|+\left|-F_{i, j}\right|}{\left|+X_{i, j}\right|+\left|-X_{i, j}\right|}$

where $K_{i, j}$ is the secant stiffness at the $i$ th loading cycle, $+F_{i, j}$ is the positive (pushing) maximum load and $+X_{i, j}$ is the homologous displacement, while $-F_{i, j}$ is the negative (pulling) maximum load and $-X_{i, j}$ is the homologous displacement in the $i$ th loading cycle at the $j$ th loading step.

Fig. 24 illustrates the secant stiffness-displacement evolution curves. All the precast specimens had a total loss of stiffness at a shorter loading displacement level compared with specimen BCJ-C. Besides, the precast specimens had a higher initial secant stiffness than specimen BCJ-C, which is also confirmed in Fig. 19b. This can be attributed to the larger stiffness of the grouted sleeves, which had a larger diameter than the longitudinal reinforcement used in the reference specimen. The specimens BCJ-1, BCJ-2, BCJ-4, and BCJ-5 had a similar rate of stiffness degradation. The specimen BCJ-3 had a slower rate of the stiffness degradation compared with other prefabricated specimens due to the increased diameter of the transition bar in specimen BCJ-3, which helped to resist the stiffness degradation significantly.

\subsection{Provisions of the flexural capacity}

In this section, a theoretical prediction of the flexural ability of the tested beam-column joints is undertaken and compared with the test results. Since the grouted sleeve splices in the proposed prefabricated beam to column joints were not subjected to bond-slip failure and the load carrying ability of the precast specimens was similar to that of the reference specimen, the design provisions for cast-in-place structures can be applied to the precast beam-column joints connected by double grouted sleeves. All specimens were subjected to a failure mode with a plastic hinge at the beam end, which shows that the load carrying capacity of the samples was controlled by the flexural capacity of the beam's cross section. Therefore, the classical flexural capacity calculation method that has been commonly used to study different components [13,63-65] can be utilized in this research. A schematic diagram for calculating the flexural capacity of the beam is given in Fig. 25 . According to the equilibrium conditions, the following equation can be obtained:

$\alpha_{1} f_{c} b x=f_{s} A_{s}-f_{s}^{\prime} A_{s}^{\prime}$

where $\alpha_{1}$ is the ratio of equivalent rectangular stress (herein, $\alpha_{1}$ is taken as 1.0 according to 
GB50010-2010 [66]), $f_{c}$ is the axial compressive strength of the concrete $\left(f_{c}=0.88 \alpha_{c 1} \alpha_{c 2} f_{c u}\right.$ where $\alpha_{1}=0.76, \alpha_{2}=1$, and $f_{c u}$ is the cubic compressive strength of the concrete according to [66]), $b$ is the width of the beam's cross-section, $f_{s}$ and $f_{s}^{\prime}$ represent the tensile and compressive strengths of the steel bars (for the specimens BCJ-1, BCJ-2 and BCJ-3, the tensile and compressive strengths were obtained from the transition bars, while for the specimens BCJ-4, BCJ-5, BCJ-S and BCJ-C, the tensile and compressive strengths were obtained from the longitudinal steel bars), $A_{S}$ and $A_{\mathrm{s}}^{\prime}$ are the corresponding areas of tension and compression steel bars, and $x$ is the balanced compressive height which should satisfy Eq. (6):

$x \geq 2 a_{s}^{\prime}$

First it is assumed that the tensile reinforcement yields, that is, $f_{s}$ takes the yield strength of the longitudinal reinforcement. When the calculated $x$ satisfies Eq. (6), it indicates that both the compressive and tensile reinforcements reach the yield strength and the assumption is valid. At this time, the maximum flexural ability $\left(M_{\text {pre }}\right)$ of the specimens can be calculated by Eq. ( 7 ). If the calculated $x$ does not satisfy Eq. (6), it indicates that the strength of the tensioned steel bar needs to be increased. Then the strength $\left(f_{s}\right)$ of the tensioned steel bar is assumed to be its ultimate strength. If $x$ calculated by Eq. (5) satisfies Eq. (6), the strength of the tensioned steel bar can be taken as its ultimate strength, and then $M_{\text {pre }}$ can be calculated by:

$M_{\text {pre }}=f_{s}^{\prime} A_{s}^{\prime}\left(h_{0}-a_{s}^{\prime}\right)+\alpha_{1} f_{c} b x\left(h_{0}-\frac{x}{2}\right)$

where $h_{0}$ is the effective height of beam's cross-section.

If the calculated $x$ still does not satisfy Eq. (6), it indicates that the compression steel bars have not yielded. According to the stipulation in GB50010-2010 [66], $M_{\text {pre }}$ can be obtained by: $M_{\text {pre }}=f_{s} A_{s}\left(h_{0}-a_{s}^{\prime}\right)$

The theoretical maximum flexural capacity of the specimens is calculated by using the above described approach and compared with the experimental results, as illustrated in Table 6. The maximum flexural capacity of the precast specimens is less than $6 \%$ compared with the test value, which reflects that the maximum flexural ability of the precast beam-column joints connected by double grouted sleeves can be well predicted by using the same maximum flexural capacity calculation method as the cast-in-situ beam-column joint. The difference between the predicted maximum flexural capacity and the measured value is only $2.62 \%$ for the specimen BCJ-3 with transition bar diameter of $18 \mathrm{~mm}$, which suggests that the load bearing capacity of the specimen BCJ-3 is equivalent to that of the cast-in-situ specimens with a longitudinal steel bar diameter of 18 $\mathrm{mm}$. It should be mentioned that the amount of steel used in the specimen BCJ-3 is less than that of the cast-in-place beam to column joint with the same bearing capacity. Therefore, it is economical to improve the load carrying ability of the proposed precast joints by increasing the transition bar diameter. However, this finding is valid for the joint with no protruding beam only if the amount of steel bars (not the transition bars) outside the long grouted sleeves is enough to resist the bending moment in front of the long grouted sleeves in the precast beam.

\section{Conclusions}

An experimental investigation was conducted to investigate the seismic performance of the prefabricated beam-to-column joints connected by double grouted sleeves. According to the present study, the following conclusions can be drawn:

- All prefabricated samples were subjected to a failure by plastic hinge deformation at the beam end and the grouted sleeve splices in all samples were not subjected to bond-slip or fracture 
failure. These indicate that it is feasible for double grouted sleeve splices to connect two disconnected precast members.

- The yield load of the prefabricated specimens was similar to that of the control specimen and increased with the increase of transition bar diameter.

- The load carrying ability of the precast specimens was similar to that of the reference specimen and was increased by $20.4 \%$ as the transition bar diameter increased from $16 \mathrm{~mm}$ to $18 \mathrm{~mm}$. It is worth mentioning that increasing the diameter of the transition bar is a good solution to improve the load carrying ability of the joints because of the short length of the transition bar and the low cost. However, this solution is only suitable for the precast joint with no protruding beam.

- The deformation capacity of the precast specimens in the ultimate limit state was lower than that of the control specimen. The ductility and deformation capacity of the precast specimens were improved with the increase of the assembly length. In addition, threads in the grouted sleeve had a negative impact on the ductility and deformation ability of the joints.

- The average ultimate cumulative dissipated energy of the prefabricated specimens is $41 \%$ lower than that of the reference specimen because of the larger stiffness of the grouted sleeves compared to conventional steel bars. With the increase of the assembly length from $0 \mathrm{~mm}$ to 425 $\mathrm{mm}$, the energy dissipation ability of the precast specimens was enhanced by $22.8 \%$ and $33.2 \%$, respectively, because of the increased plastic hinge length. As the transition bar diameter increased from $16 \mathrm{~mm}$ to $18 \mathrm{~mm}$, the energy dissipation capacity of the precast specimen was increased by $64.8 \%$. Therefore, increasing the diameter of the transition bar to enhance the energy dissipation of the precast joint is an effective and economic measure due to the short length of the transition bar. But this measure is only applicable to the connection with no protruding beam. Additionally, threads to provide interlocking mechanism in GSWT have a negative impact on the energy dissipation of the precast joints compared with GSW.

The precast beam-column joint connected by double grouted sleeves is a new type of connection. To acquire a further understanding of the structural behaviour of the joint under different loading conditions, it is necessary to conduct numerical simulations and analytical analysis. This is a subject of ongoing work and will be presented in a future publication.

\section{Acknowledgments}

The authors gratefully acknowledge financial support from the Yellow Crane Meritocracy Plan of Wuhan (Grant No. 20161j0013), the Scientific and Technological Plan Project of Wuhan Urban and Rural Construction Commission (Grant No. 201812), the Hubei Province Construction Science and Technology Plan Project (Grant No. 20171103), and the State Key Laboratory of Silicate Materials for Architectures (Wuhan University of Technology) (Grant No. SYSJJ2018-08).

\section{References}

[1] Ameli MJ, Brown DN, Parks JE, Pantelides CP. Seismic column-to-footing connections using grouted splice sleeves. ACI Structural Journal 2016;113(5):1021-1030.

[2] Priestley MJN. Overview of PRESSS research program. PCI Journal 1991;36(4):50-57.

[3] Guan DZ, Cheng J, Guo ZX, Ge HB. Development and seismic behavior of precast concrete beam-to-column connections. Journal of Earthquake Engineering 2016;22(2):234-256.

[4] Yan QS, Chen TY, Xie ZY. Seismic experimental study on a precast concrete beam-column connection with grout sleeves. Engineering Structures 2018;155:330-344.

[5] Feng DC, Wu G, Lu Y. Finite element modelling approach for precast reinforced concrete beam-to-column connections under cyclic loading. Engineering Structures 2018;174: 49-66. 
[6] Ersoy U, Tankut T. precast concrete members with welded plate connections under reversed cyclic loading. PCI Journal 1993;38(4):94-100.

[7] Korkmaz HH, Tankut T. Performance of a precast concrete beam-to-beam connection subject to reversed cyclic loading. Engineering Structures 2005;27(9):1392-1407.

[8] Xiao JZ, Ding T, Zhang QT. Structural behavior of a new moment-resisting DfD concrete connection. Engineering Structures 2017;132:1-13.

[9] Li B, Kulkarni SA, Leong CL. Seismic performance of precast hybrid-steel concrete connections. Journal of Earthquake Engineering 2009;13(5):667-689.

[10] Choi HK, Choi YC, Choi CS. Development and testing of precast concrete beam-to-column connections. Engineering Structures 2013;56:1820-1835.

[11] Ghayeb HH, Razak HA, Sulong NHR. Development and testing of hybrid precast concrete beam-to-column connections under cyclic loading. Construction and Building Materials 2017; 151:258-278.

[12] Bahrami S, Madhkhan M, Shirmohammadi F, Nazemi N. Behavior of two new moment resisting precast beam to column connections subjected to lateral loading. Engineering Structures 2017;132:808-821.

[13] Li SF, Li QL, Zhang H, Jiang HT, Yan L, Jiang WS. Experimental study of a fabricated confined concrete beam-to-column connection with end-plates. Construction and Building Materials 2018;158:208-216.

[14] Nzabonimpa JD, Hong WK, Kim J. Experimental and non-linear numerical investigation of the novel detachable mechanical joints with laminated plates for composite precast beam-column joint. Composite Structures 2018;185:286-303.

[15] Henin E, Morcous G. Non-proprietary bar splice sleeve for precast concrete construction. Engineering Structures 2015;83:154-162.

[16] Parastesh H, Hajirasouliha I, Ramezani R. A new ductile moment-resisting connection for precast concrete frames in seismic regions: An experimental investigation. Engineering Structures 2014;70:144-157.

[17] Guan DZ, Guo ZX, Xiao QD, Zheng YF. Experimental study of a new beam-to-column connection for precast concrete frames under reversal cyclic loading. Advances in Structural Engineering 2016;19(3):529-545.

[18] Lu C, Dong BQ, Pan JL, Shan QF, Hanif A, Yin Wanyun. An investigation on the behavior of a new connection for precast structures under reverse cyclic loading. Engineering Structures 2018;169:131-140.

[19] Alias A, Sapawi F, Kusbiantoro A, Zubir MA, Abd Rahman AB. Performance of grouted splice sleeve connector under tensile load. Journal of Mechanical Engineering and Sciences 2014;7:1094-1102.

[20] Ling JH, Abd Rahman AB, Ibrahim IS. Feasibility study of grouted splice connector under tensile load. Construction and Building Materials 2014;50(1):530-539.

[21] Priestley MJN, Tao JR. Seismic response of precast prestressed concrete frames with partially debonded tendons. PCI Journal 1993;38(1):58-69.

[22] Priestley MJN, Sritharan SS, Conley JR, Pampanin S. Preliminary results and conclusions from the PRESSS five-story precast concrete test building. PCI Journal 1999;44(6):42-67.

[23] Nakaki SD, Stanton JF, Sritharan SS. An overview of the PRESSS five-story precast test building. PCI Journal 1999;44(2):26-39. 
[24] Ozden S, Ertas O. Behavior of unbonded, post-tensioned, precast concrete connections with different percentages of mild steel reinforcement. PCI Journal 2007;52(2):32-44.

[25] Alver N, Selman ME, Akgun OB. The effect of short cantilever beam formation on the structural behavior of precast post-tensioned connections. Construction and Building Materials 2012;35:232-239.

[26] Kaya M, Arslan AS. The effect of the diameter of prestressed strands providing the post-tensioned beam-to-column connections. Materials and Design 2009;30(7):2604-2617.

[27] Wang HS, Marino EM, Pan P, Liu H, Nie X. Experimental study of a novel precast prestressed reinforced concrete beam-to-column joint. Engineering Structures 2018;156:68-81.

[28] Koshikawa T. Moment and energy dissipation capacities of post-tensioned precast concrete connections employing a friction device. Engineering Structures 2017;138:170-180.

[29] Stone WC, Cheek GS, Stanton JF. Performance of hybrid moment-resisting precast beam-column concrete connections subjected to cyclic loading. ACI Structural Journal 1995;92(2):229-249.

[30] Morgen BG, Kurama YC. A friction damper for post-tensioned precast concrete beam-to-column joints. PCI Journal 2004;49(4)112-133.

[31] Song LL, Guo T, Chen C. Experimental and numerical study of a self-centering prestressed concrete moment resisting frame connection with bolted web friction devices. Earthquake Engineering \& Structural Dynamics 2014;43(4):529-45.

[32] Song LL, Guo T, Gu Y, Cao ZL. Experimental study of a self-centering prestressed concrete frame subassembly. Engineering Structures 2015;88:176-188.

[33] Rodgers GW, Solberg KM, Chase JG, Mander JB, Bradley BA, Dhakal RP, et al. Performance of a damage-protected beam-column subassembly utilizing external HF2V energy dissipation devices. Earthquake Engineering \& Structural Dynamics. 2008;37(13):1549-1564.

[34] Rodgers GW, Solberg KM, Mander JB, Chase JG, Bradley BA, Dhakal RP. High-force-to-volume seismic dissipators embedded in a jointed precast concrete frame. Journal of Structural Engineering 2012;138(3):375-86.

[35] Englekirk RE. Overview of PCI workshop on effective use of precast concrete for seismic resistance. PCI Journal 1986;31(6):48-58.

[36] Mezzapelle PA, Scalbi A, Clementi F, Lenci S. The influence of dowel-pin connections on the seismic fragility assessment of RC precast industrial buildings. The Open Civil Engineering Journal 2017;11:1138-1157.

[37] Clementi F, Scalbi A, Lenci S. Seismic performance of precast reinforced concrete buildings with dowel pin connections. Journal of Building Engineering 2016;7:224-238.

[38] Kremmyda GD, Fahjan YM, Tsoukantas SG. Nonlinear FE analysis of precast RC pinned beam-to-column connections under monotonic and cyclic shear loading. Bulletin of Earthquake Engineering 2014;12(4):1615-1638.

[39] Zoubek B, Isakovic T, Fahjan Y, Fischinger M. Cyclic failure analysis of the beam-to-column dowel connections in precast industrial buildings. Engineering Structures 2013;52:179-191.

[40] Huang Y, Zhu ZG, Clay JN, Yi WJ. Tensile behavior of half grouted sleeve connections: Experimental study and analytical modeling. Construction and Building Materials 2017;152:96-104.

[41] Einea A, Yamane T, Tadros MK. Grout-filled pipe splices for precast concrete construction. PCI Journal 1995;40(1):82-93. 
[42] Sayadi AA, Abd Rahman AB, Bin Jumaat MZ, Alengaram UJ, Ahmad S. The relationship between interlocking mechanism and bond strength in elastic and inelastic segment of splice sleeve. Construction and Building Materials. 2014;55:227-237.

[43] Abd Rahman AB, Yoon LH, Ibrahim IS, Mohamed RN, Mohammad S, Saim AA. Performance of grouted splice sleeves with tapered bars under axial tension. Applied Mechanics and Materials 2015;789-790:1176-1180.

[44] Lin F, Wu XB. Mechanical performance and stress-strain relationships for grouted splices under tensile and cyclic loadings. International Journal of Concrete Structures and Materials 2016;10(4):435-450.

[45] Zheng YF, Guo ZX, Liu JB, Chen XN, Xiao QD. Performance and confining mechanism of grouted deformed pipe splice under tensile load. Advances in Structural Engineering 2016;19(1):86-103.

[46] Parks JE, Papulak T, Pantelides CP. Acoustic emission monitoring of grouted splice sleeve connectors and reinforced precast concrete bridge assemblies. Construction and Building Materials 2016;122:537-547.

[47] Lu Z, Wang ZX, Li JB, Huang B. Studies on seismic performance of precast concrete columns with grouted splice sleeve. Applied Sciences 2017;7:571.

[48] Ameli MJ, Parks JE, Brown DN, Pantelides CP. Seismic evaluation of grouted splice sleeve connections for reinforced precast concrete column-to-cap beam joints in accelerated bridge construction. PCI Journal 2015;60(2):80-103.

[49] Haber ZB, Saiidi MS, Sanders DH. Seismic performance of precast columns with mechanically spliced column-footing connections. ACI Structural Journal 2014;111(3):639-650.

[50] Xu L, Pan JL, Cai JM. Seismic performance of precast RC and RC/ECC composite columns with grouted sleeve connections. Engineering Structures 2019;188:104-110.

[51] Lu Z, Huang J, Li Y, Dai S, Peng Z, Liu X, Zhang M. Mechanical behaviour of grouted sleeve splice under uniaxial tensile loading. Engineering Structures 2019;186:421-435.

[52] JG/T408-2013. Cementitious grout for coupler of rebar splicing. Beijing: Standards Press of China; 2013.

[53] GB/T17671-1999. Method of testing cements-determination of strength. Beijing: The State Bureau of Quality and Technical Supervision; 1999.

[54] JGJ/T101-2015, Specification of Testing Methods for Earthquake Resistant Building, China Architecture and Building Press, Beijing, China, 2015.

[55] Peng Z, Dai SB, Pi YL, Li DX, Zhang YC, Huang J. Seismic behaviour of innovative ring-bar reinforced connections composed of T-shaped CFST columns and RC beams with slabs. Thin-Walled Structures 2018;127:1-16.

[56] Alva GMS, El Debs ALHD. Application of lumped dissipation model in nonlinear analysis of reinforced concrete structures. Engineering Structures 2010;32(4):974-981.

[57] Sharbatdar MK, Kheyroddin A, Emami E. Cyclic performance of retrofitted reinforced concrete beam-column joints using steel prop. Construction and Building Materials 2012;36:287-294.

[58] Germano F, Tiberti G, Plizzari G. Experimental behavior of SFRC columns under uniaxial and biaxial cyclic loads. Composites Part B: Engineering 2016;85:76-92.

[59] Peng Z, Dai SB, Pi YL, Zhang YC, Huang J. Seismic performance of end-plate connections between T-shaped CFST columns and RC beams. Journal of Constructional Steel Research 
2018;145:67-183.

[60] Zhou QJ. Structural Design and Construction of Steel-concrete Composite Structure, China Architecture \& Building Press, Beijing, 1991.

[61] Zenunovic' D, Folic' R. Models for behavior analysis of monolithic wall and precast or monolithic floor slab connections. Engineering Structures 2012;40:466-478.

[62] Chopra AK. Dynamic of structures-theory and applications to earthquake engineering, 4th ed.; Prentice Hall:Upper Saddle River, NJ, USA, 2012.

[63] Yang Y, Xue YC, Yu YL, Gao FQ. Experimental study on seismic performance of partially precast steel reinforced concrete columns. Engineering Structures 2018;175:63-75.

[64] Fan X, Zhang M. Behaviour of inorganic polymer concrete columns reinforced with basalt FRP bars under eccentric compression: An experimental study. Composites Part B: Engineering 2016;104:44-56.

[65] Fan X, Zhang M. Experimental study on flexural behaviour of inorganic polymer concrete beams reinforced with basalt rebar. Composites Part B: Engineering 2016;93:174-183.

[66] GB50010-2010. Code for design of concrete structures. Beijing: China Architecture and Building Press; 2010. 


\section{Figures}

(a)

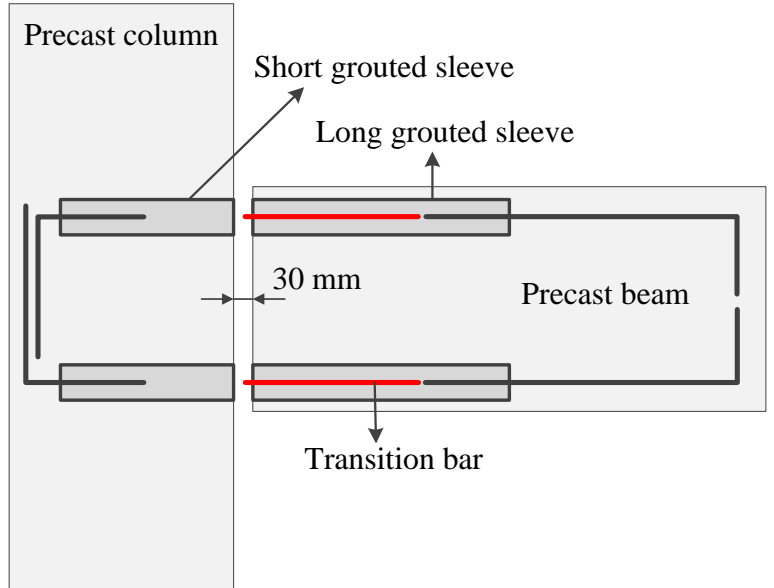

(b)

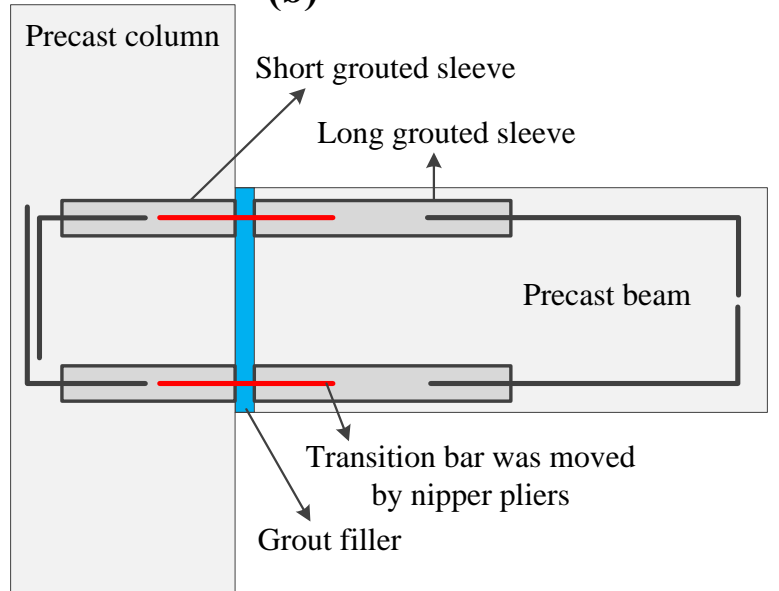

Fig. 1. Schematic diagram of the proposed precast beam-column connection: (a) precast column and beam in place; (b) move the transition bar from long grouted sleeves embedded in precast beam to short grouted sleeves embedded in precast column and keep the same length of transition bar in the long and short grouted sleeves, grout the grouted sleeve and the filler.

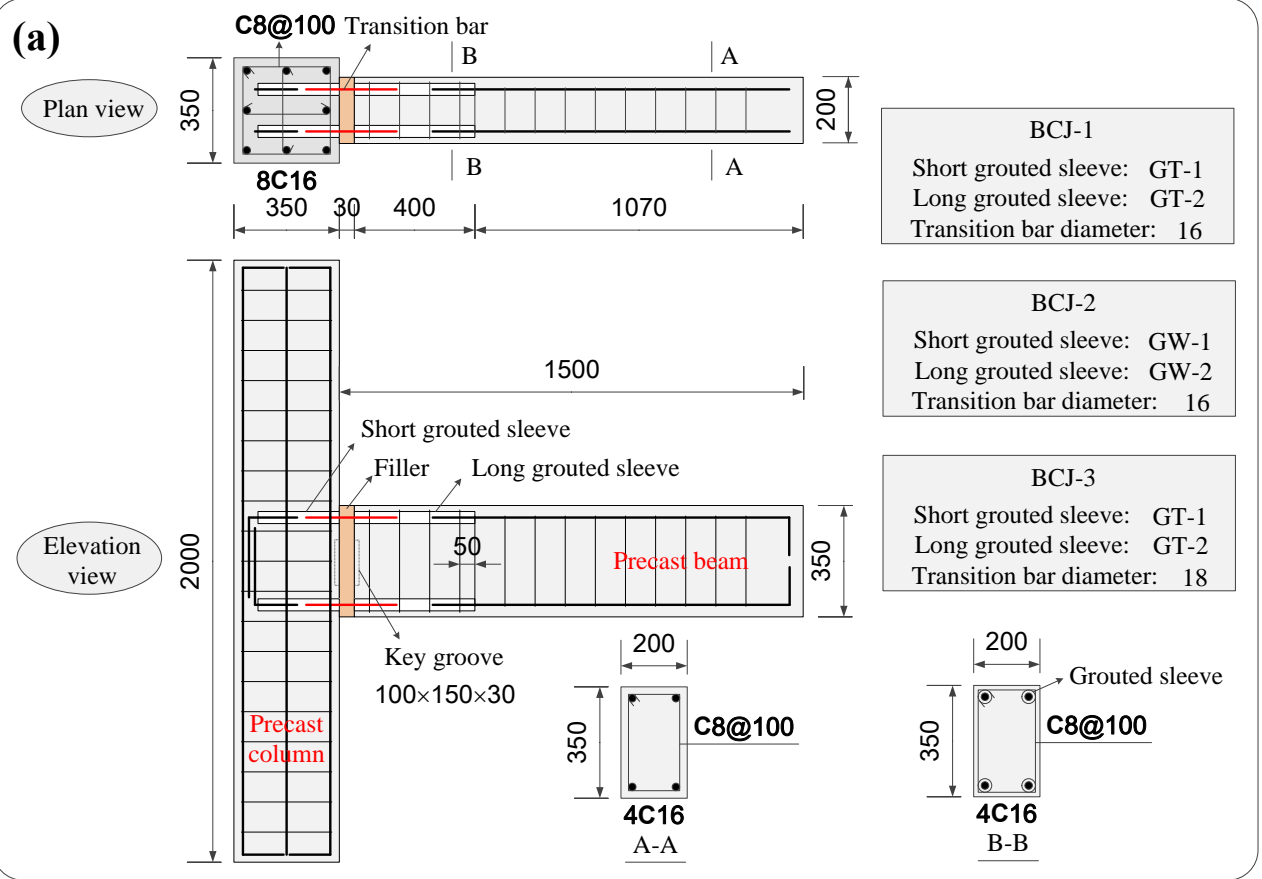



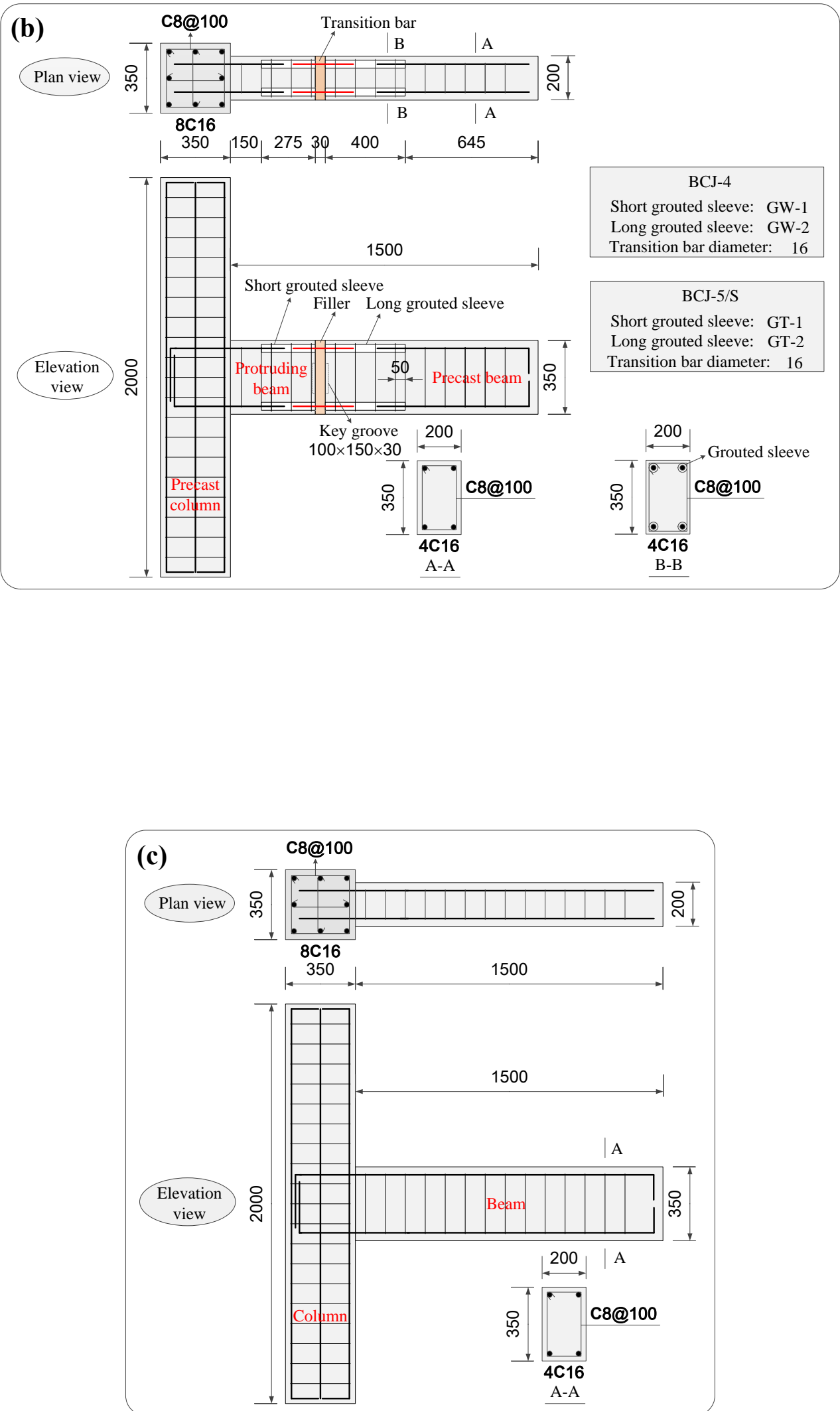

Fig. 2. Details of specimens (in mm): (a) BCJ-1, BCJ-2 and BCJ-3; (b) BCJ-4, BCJ-5 and BCJ-S; (c) control specimen, BCJ-C. 

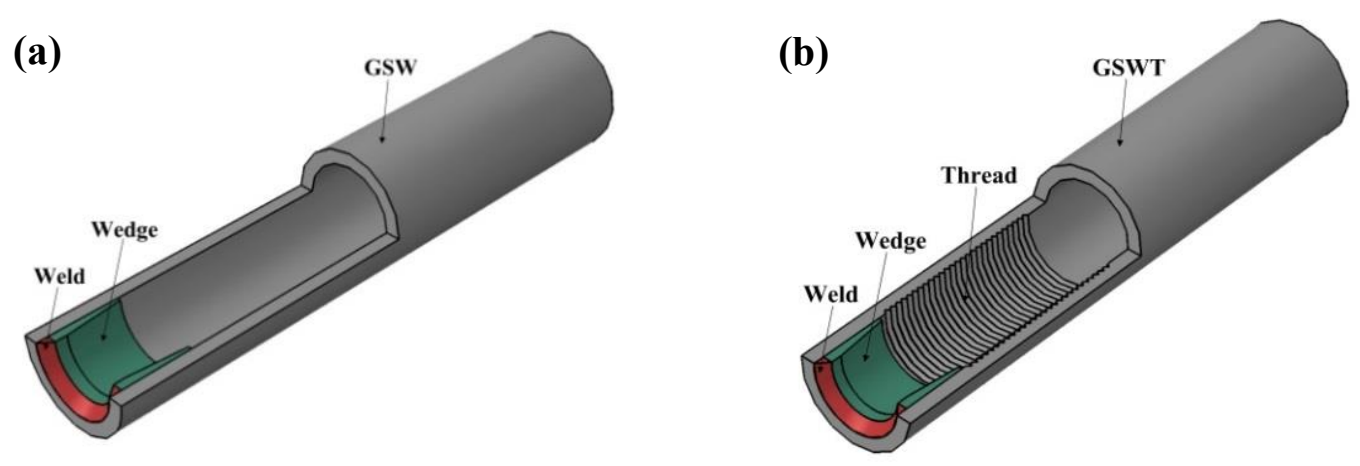

Fig. 3. Schematic diagram of grouted sleeves: (a) GSW; (b) GSWT.

(a)

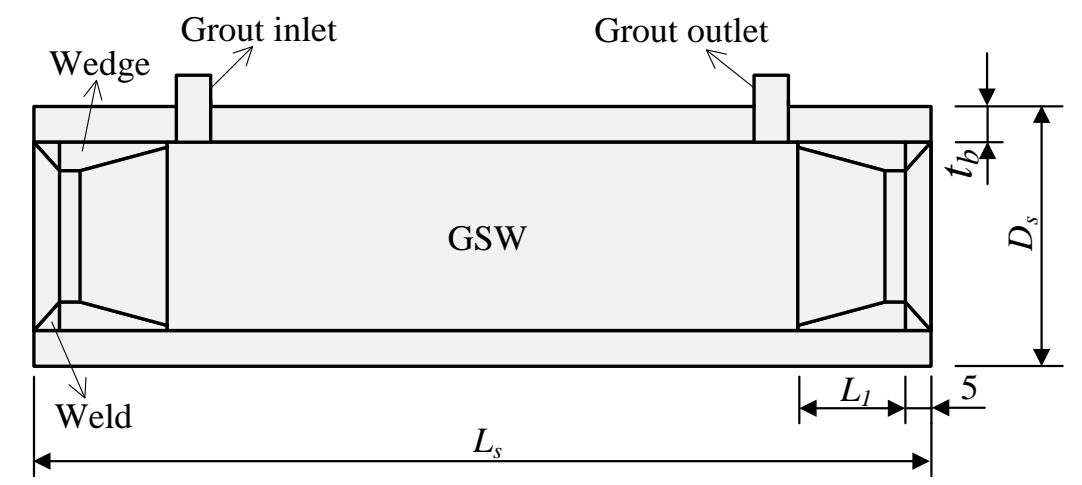

(b)

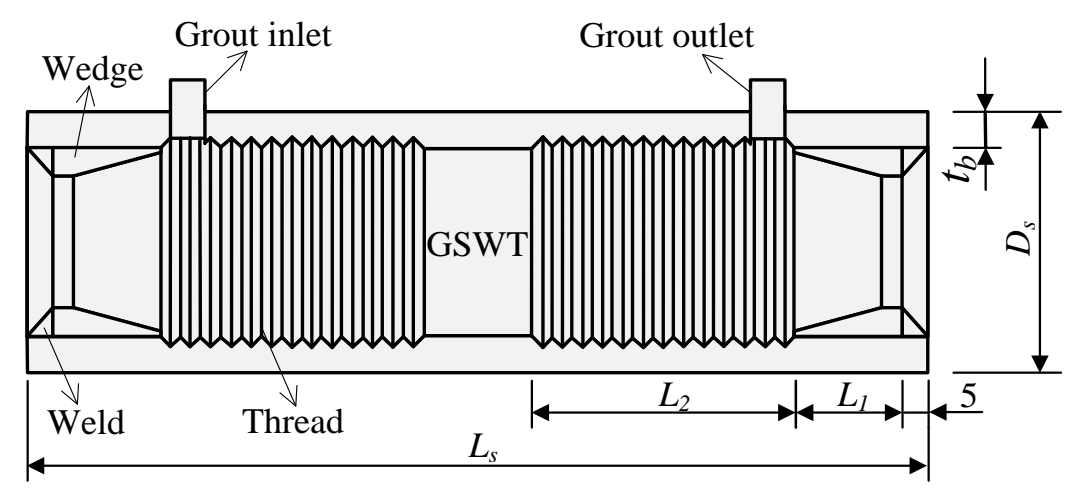

Fig. 4. Details of grouted sleeves: (a) GSW (GW-1 and GW-2); (b) GSWT (GT-1 and GT-2). 


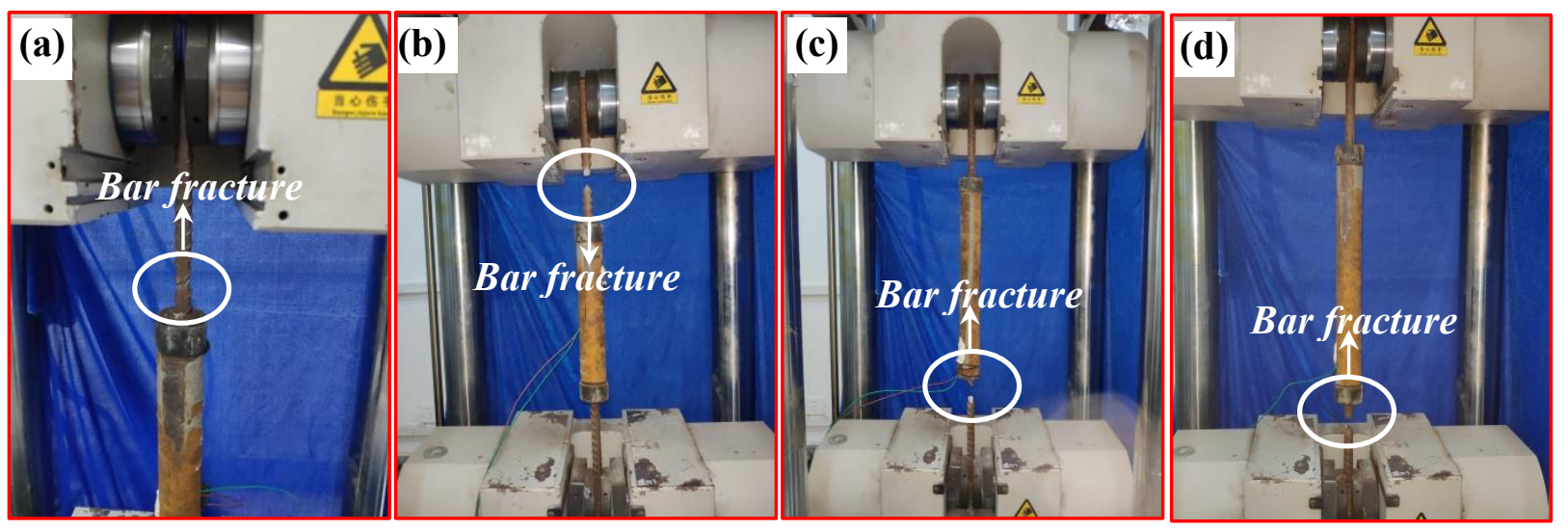

Fig. 5. Failure modes of grouted sleeve splices: (a) short GSW (GW-1); (b) short GSWT (GT-1); (c) long GSW (GW-2); (d) long GSWT (GT-2).
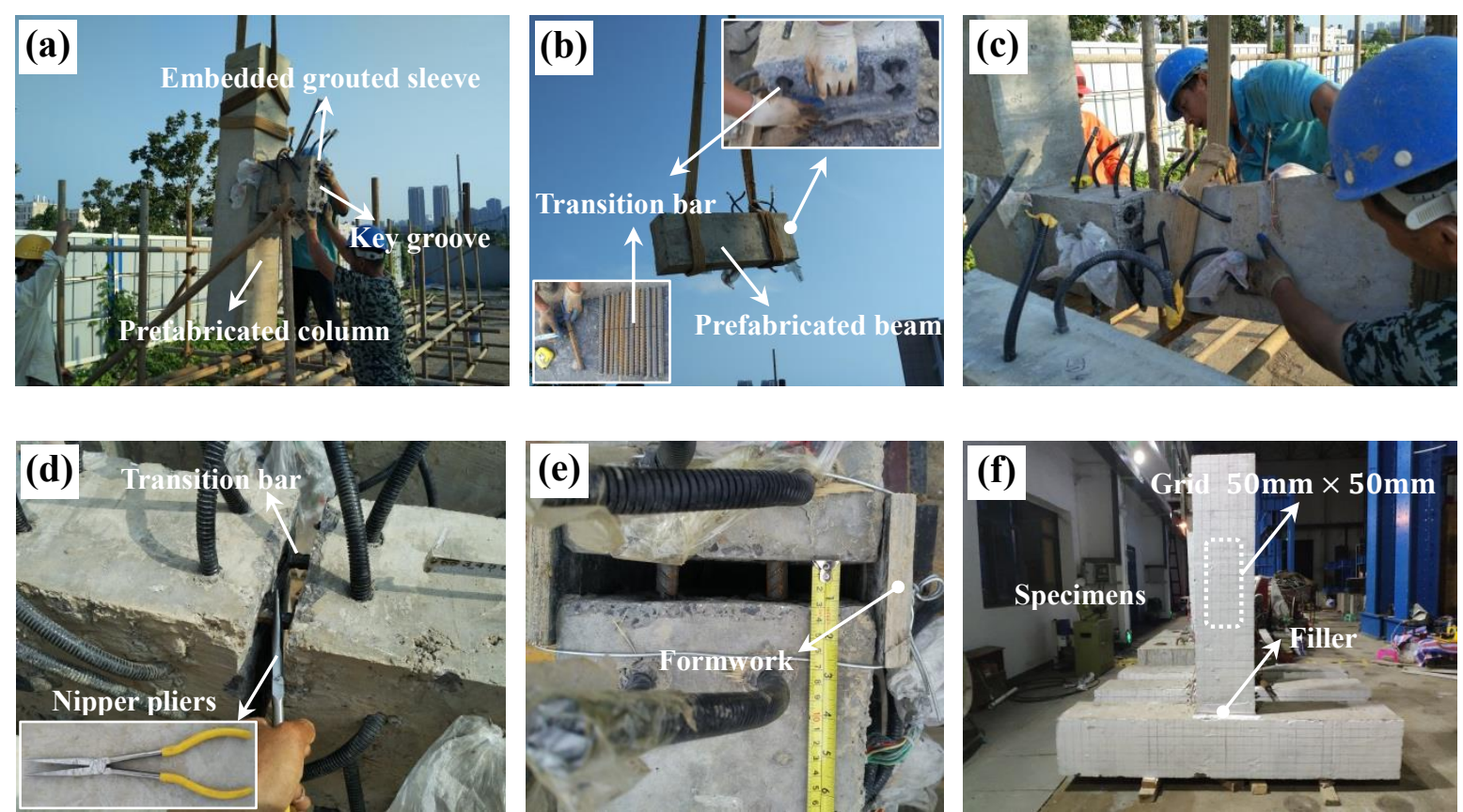

Fig. 6. Fabrication of precast specimen: (a) hoist prefabricated column; (b) lift prefabricated beam;

(c) adjust the prefabricated members to design position; (d) transition bar construction; (e) formwork construction; (f) precast specimens after grouting the sleeve and filler, whitewashing and drawing grid in order to observe cracks easily. 

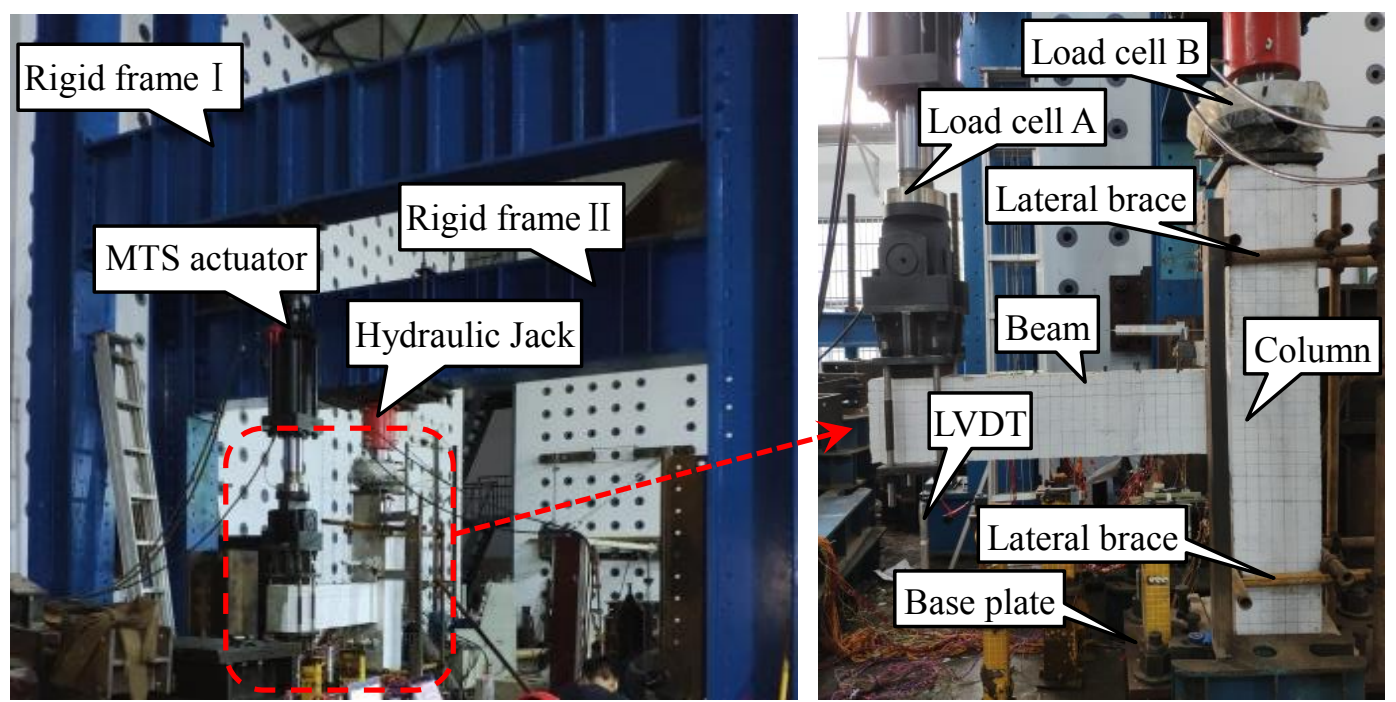

Fig. 7. A general view of the test setup.

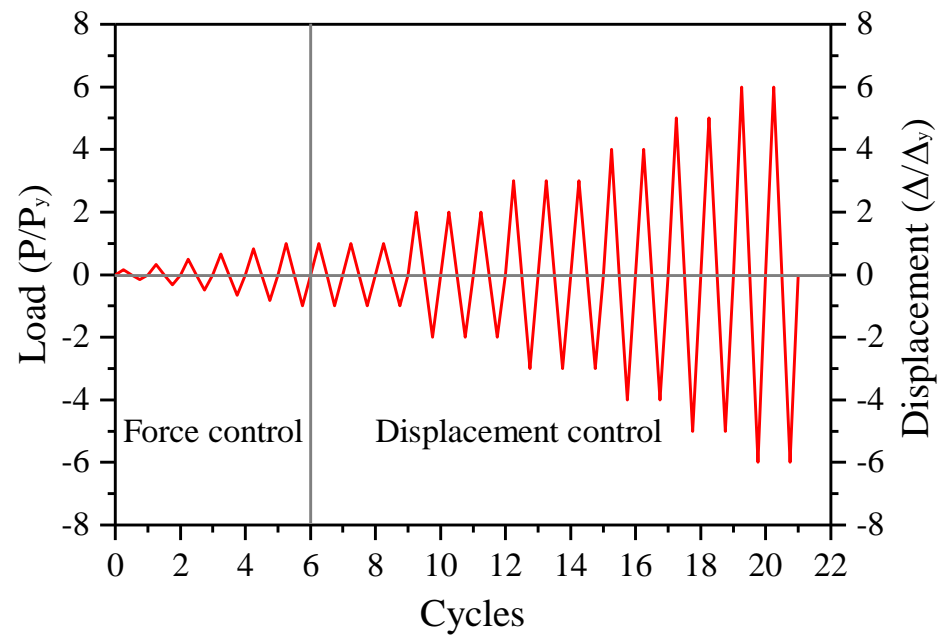

Fig. 8. Loading protocol. 


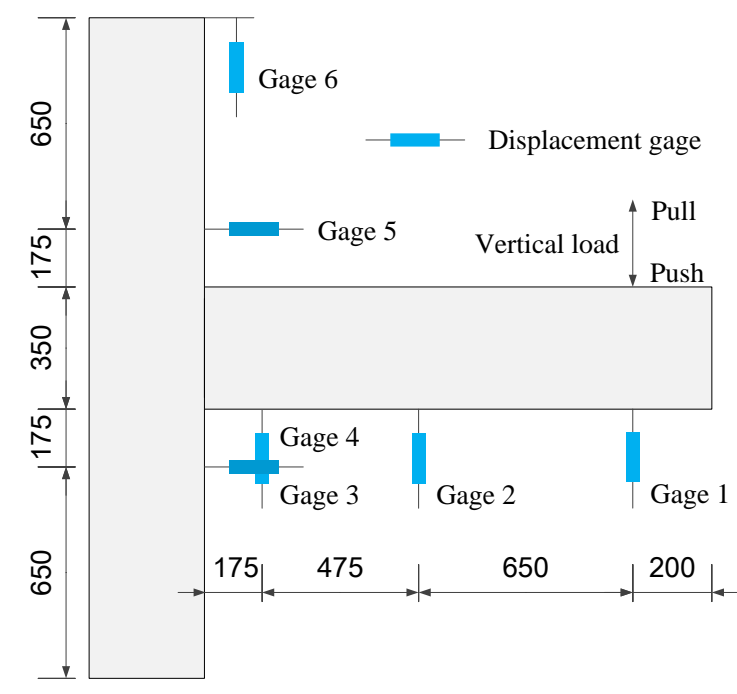

Fig. 9. Arrangement of displacement gages.

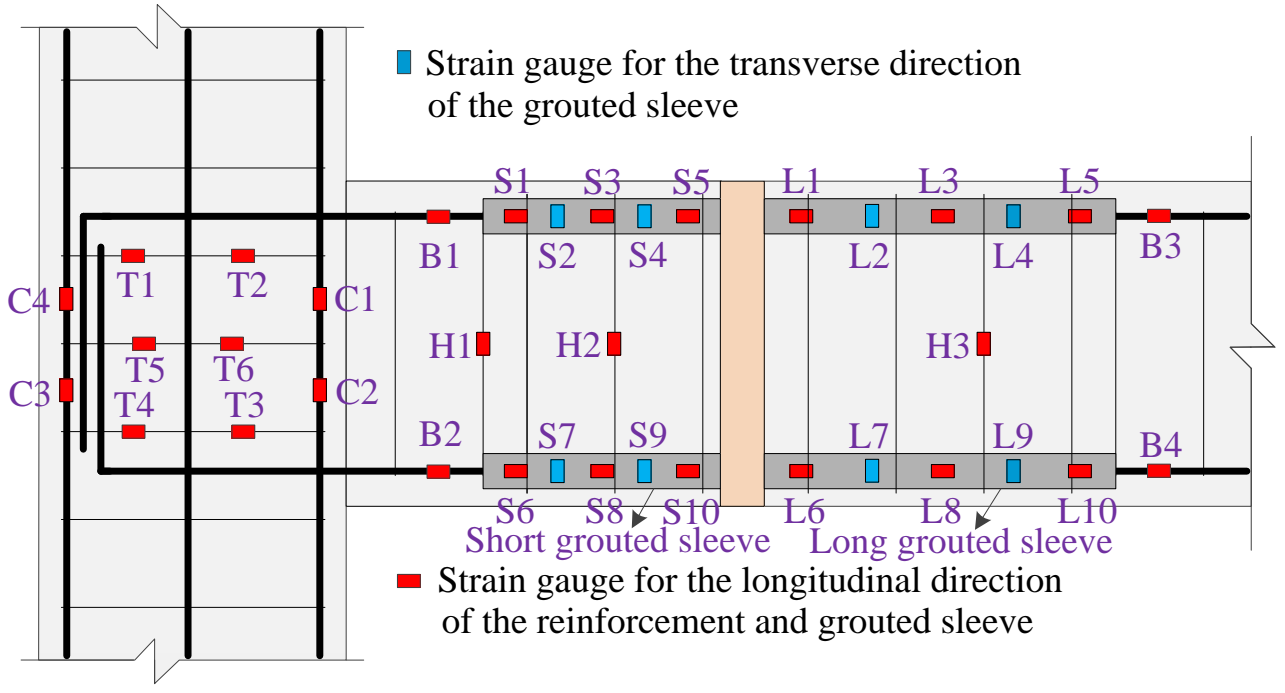

Fig. 10. Arrangement of strain gauges of the specimen BCJ-S. 

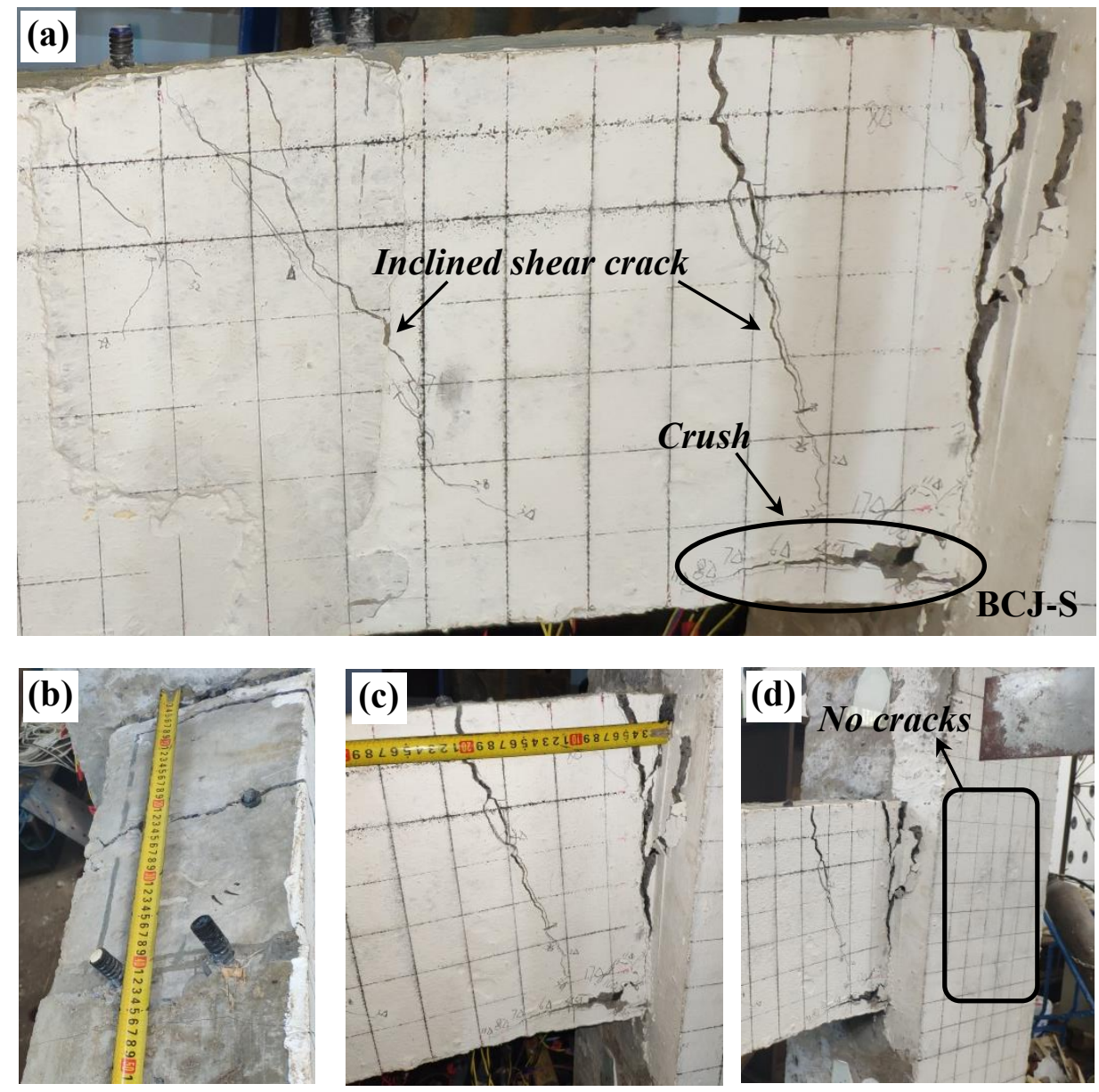

Fig. 11. Failure modes of BCJ-S: (a) beam; (b) top of beam; (c) local area of beam; (d) joint core region.

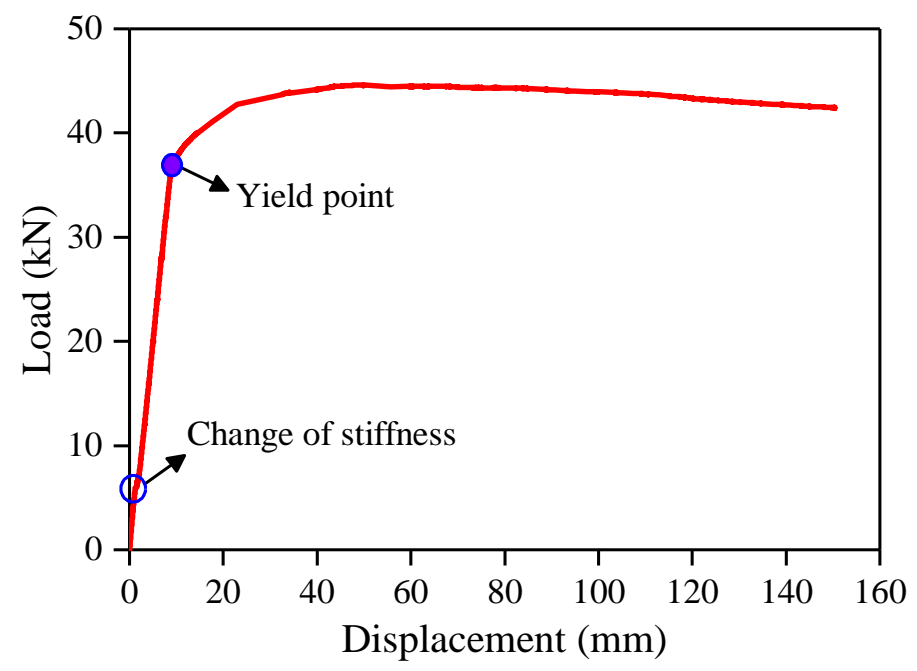

Fig. 12. Load-displacement response of the specimen BCJ-S. 
(a)

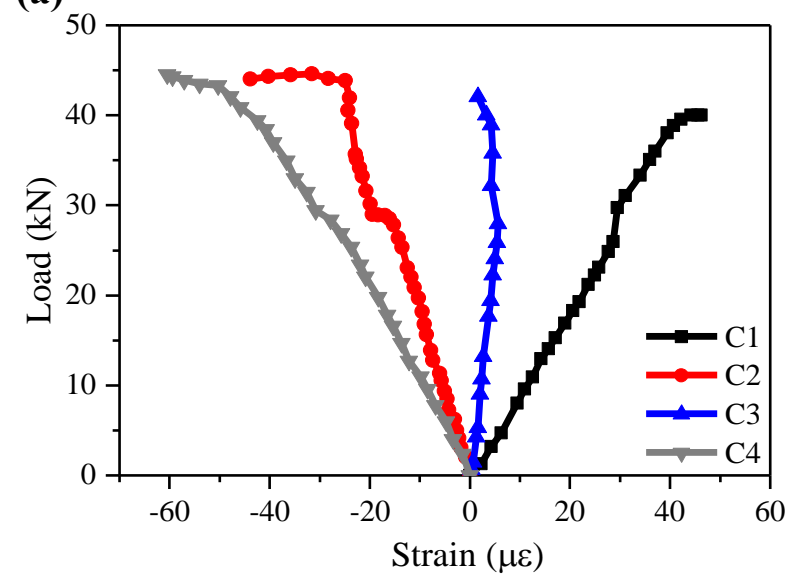

(b)

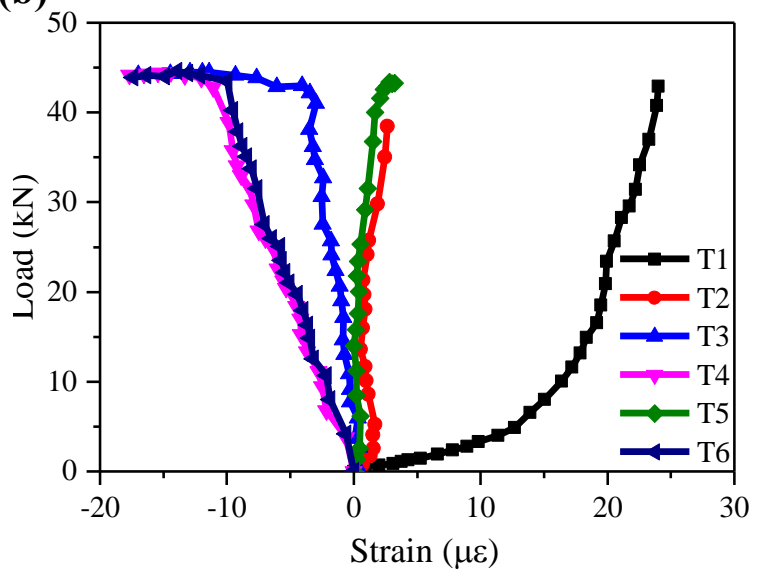

Fig. 13. Load-strain response of column for BCJ-S: (a) longitudinal reinforcement; (b) stirrup.

(a)

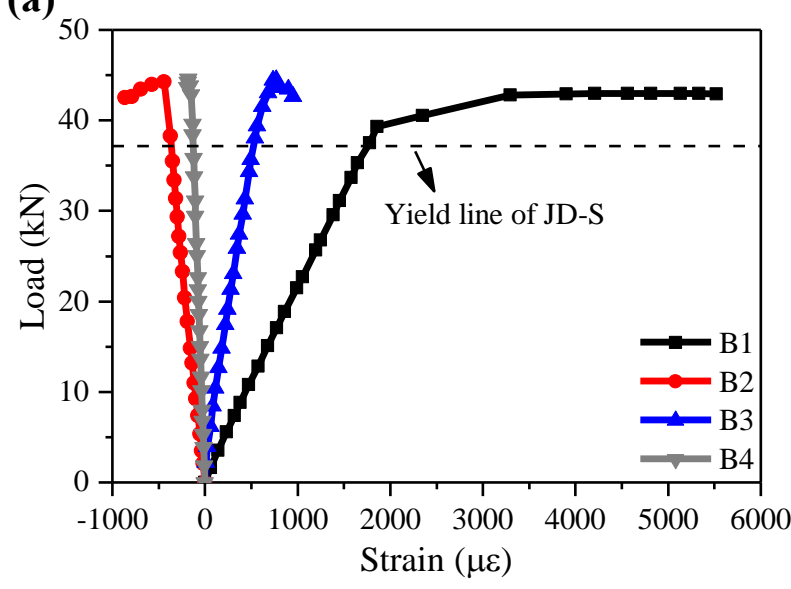

(b)

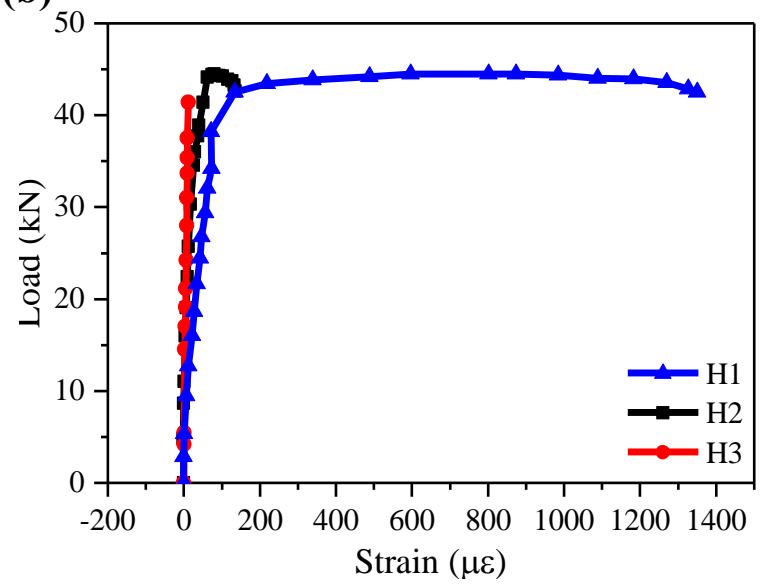

Fig. 14. Load-strain response of beam for BCJ-S: (a) longitudinal reinforcement; (b) stirrup. 

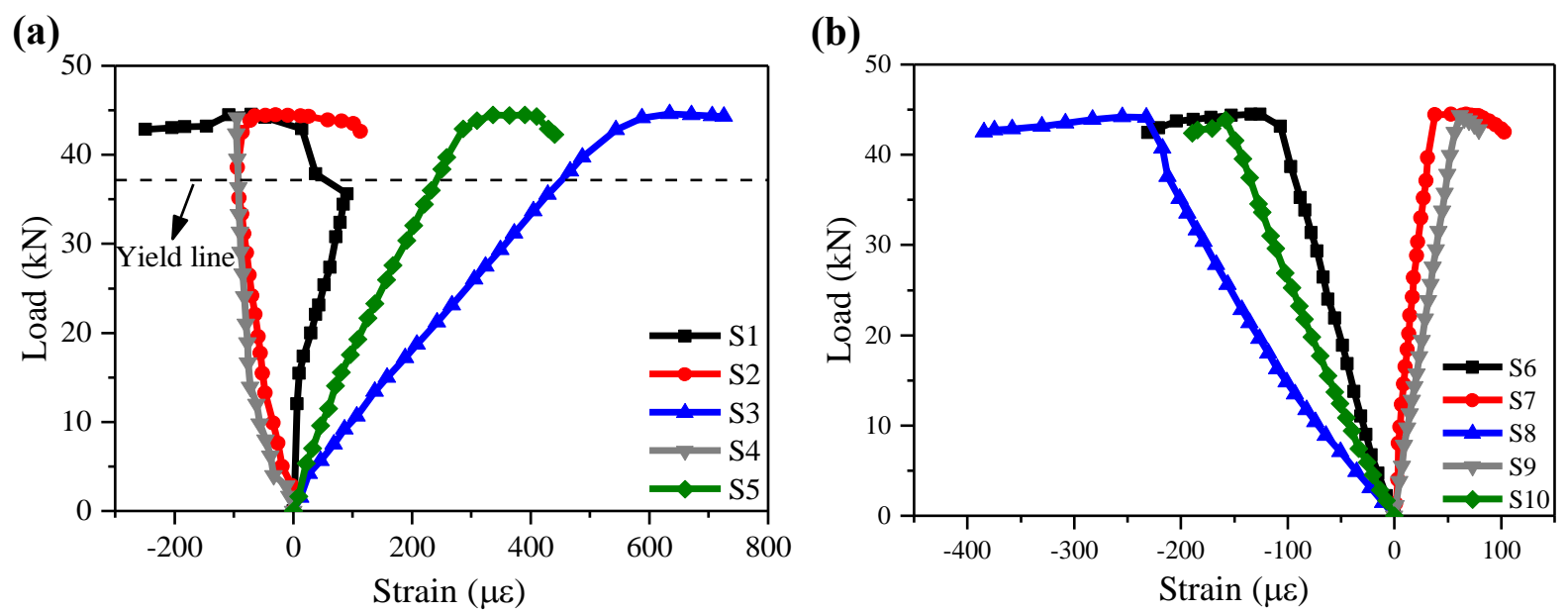

Fig. 15. Load-strain response of the short grouted sleeve for the specimen BCJ-S: (a) tension face; (b) compression face.
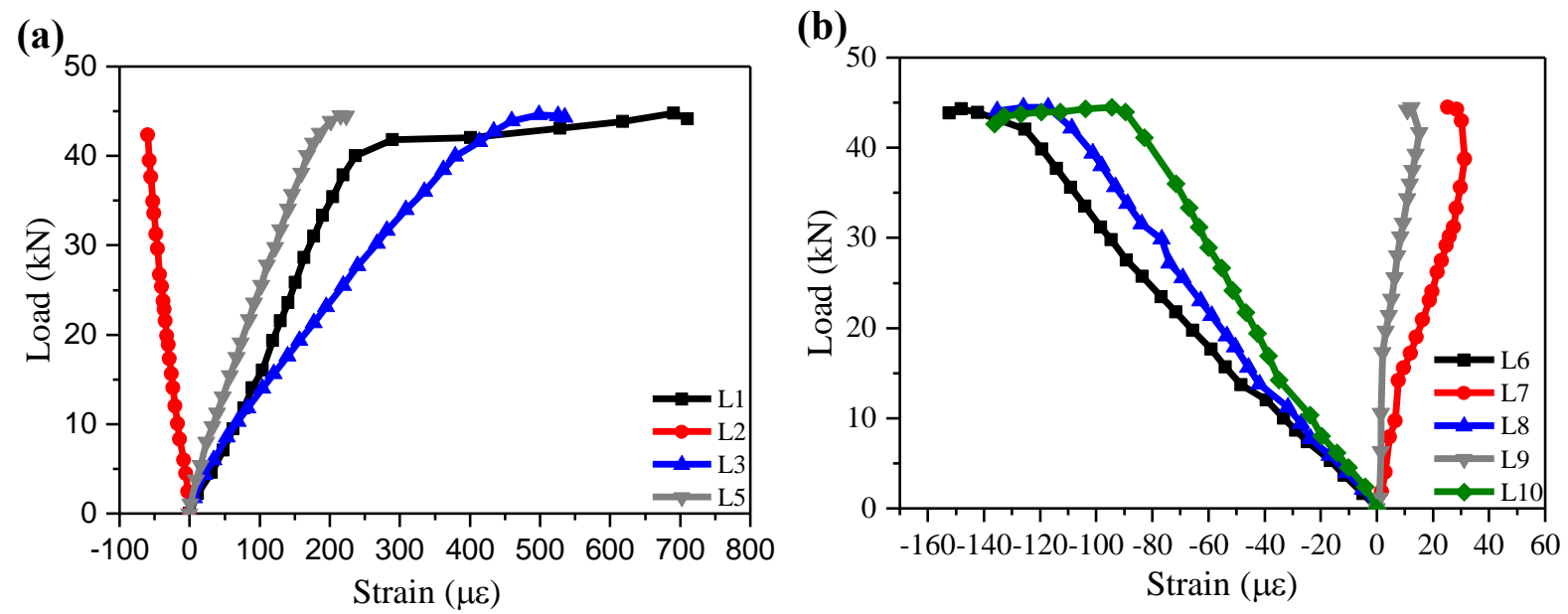

Fig. 16. Load-strain response of the long grouted sleeve for the specimen BCJ-S: (a) tension face; (b) compression face. 

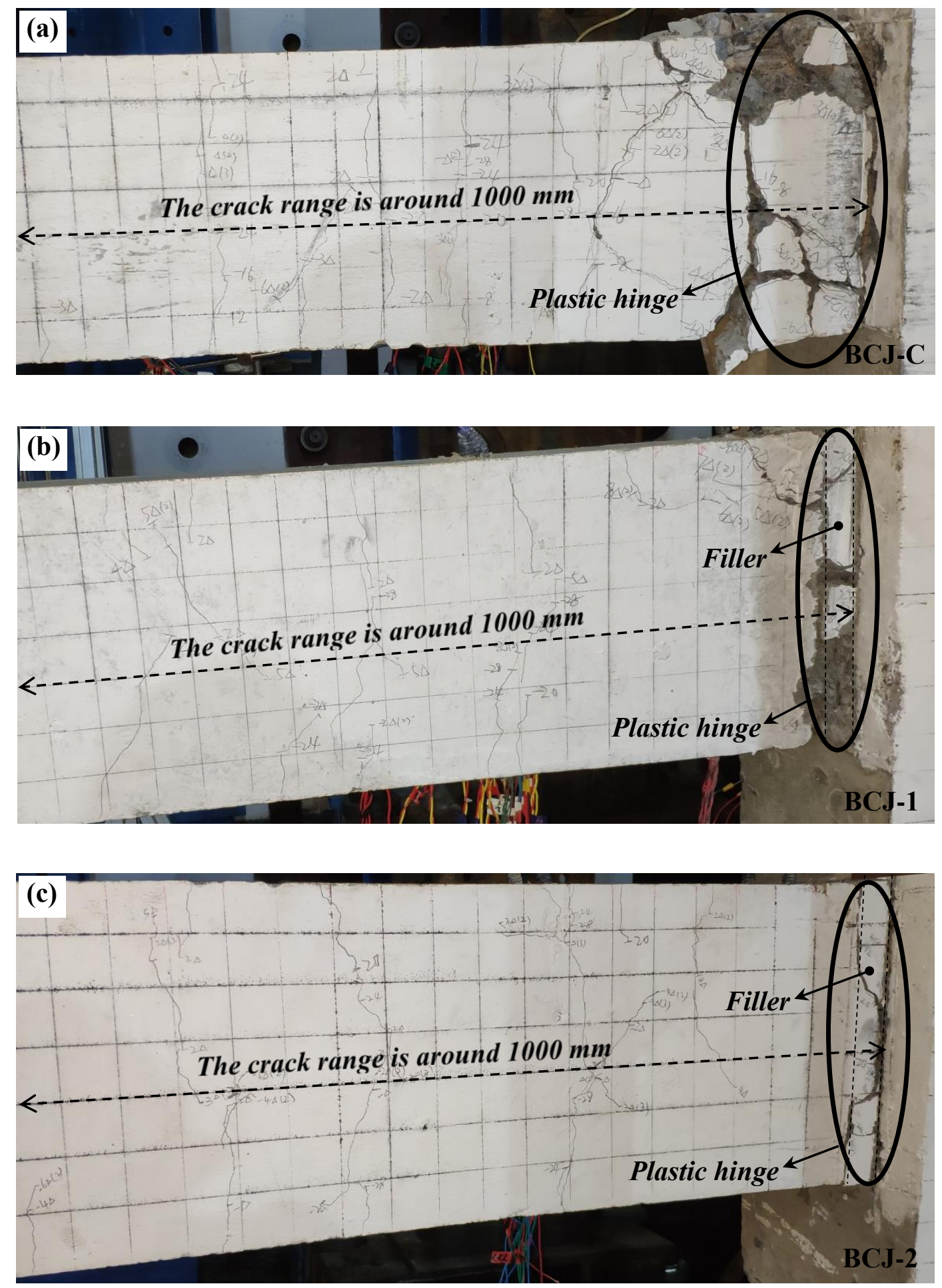

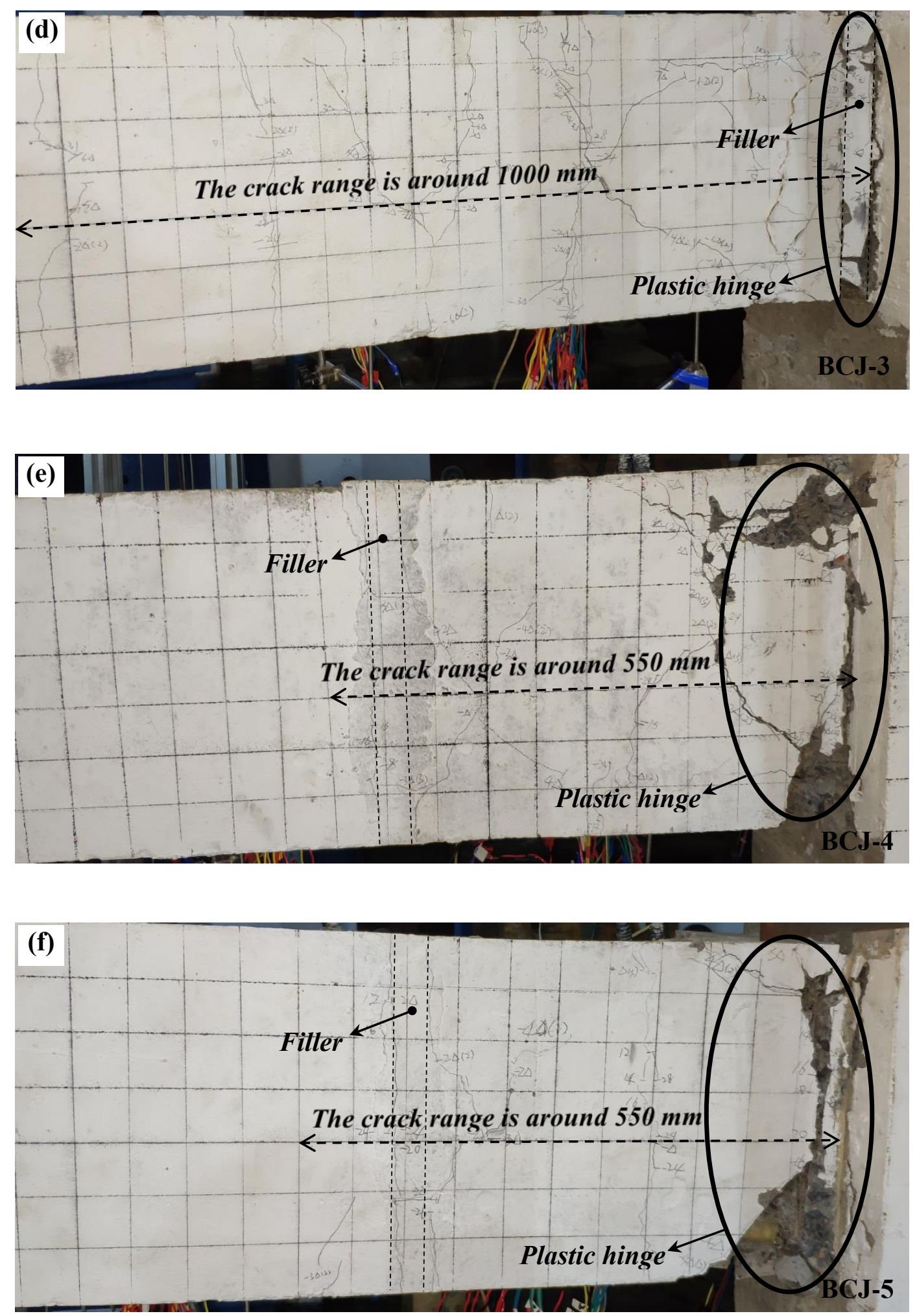

Fig. 17. Failures of control and precast specimens under cyclic loading: (a) BCJ-C; (b) BCJ-1; (c) BCJ-2; (d) BCJ-3; (e) BCJ-4; (f) BCJ-5. 

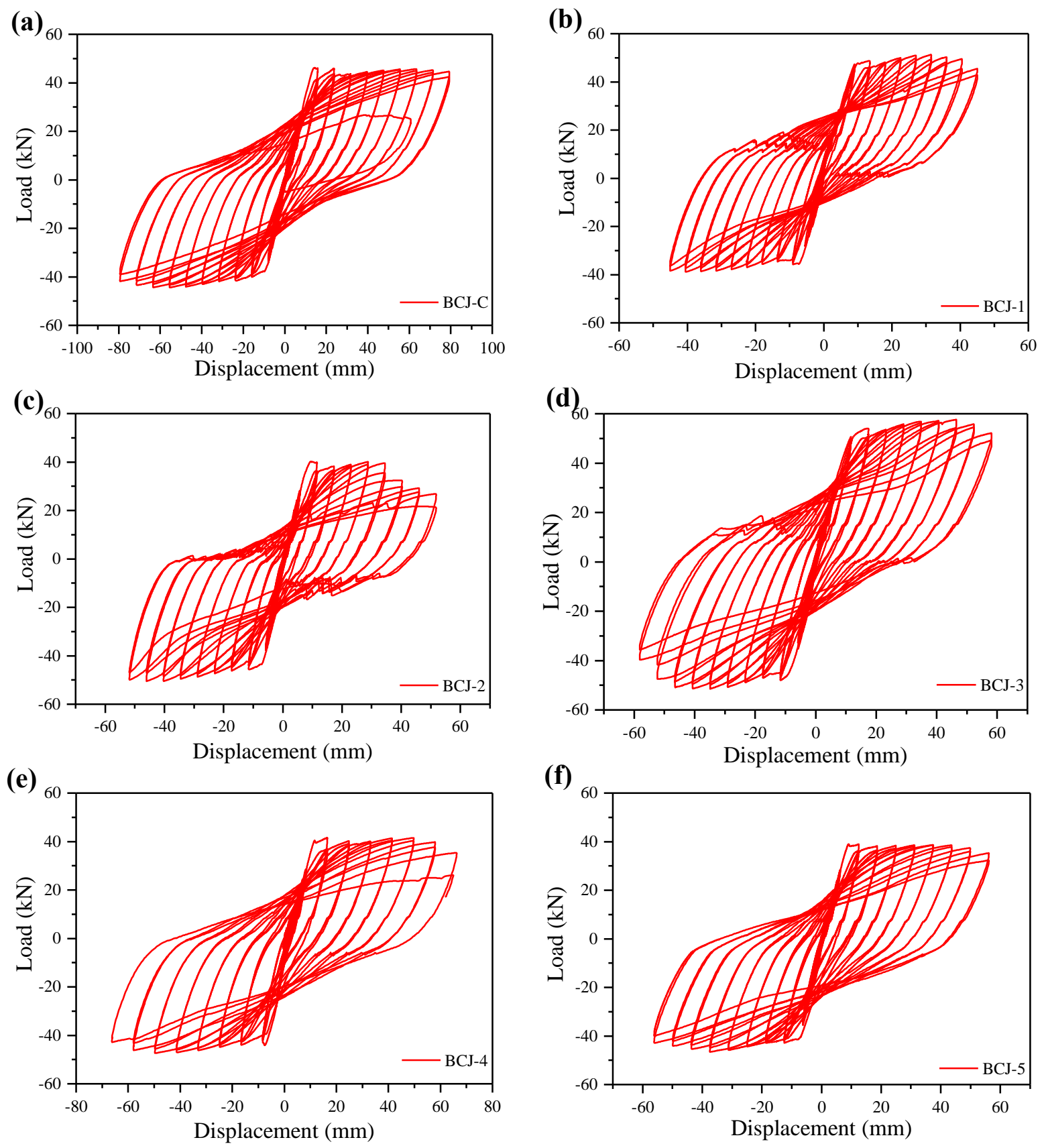

Fig. 18. Hysteretic response. 
(a)

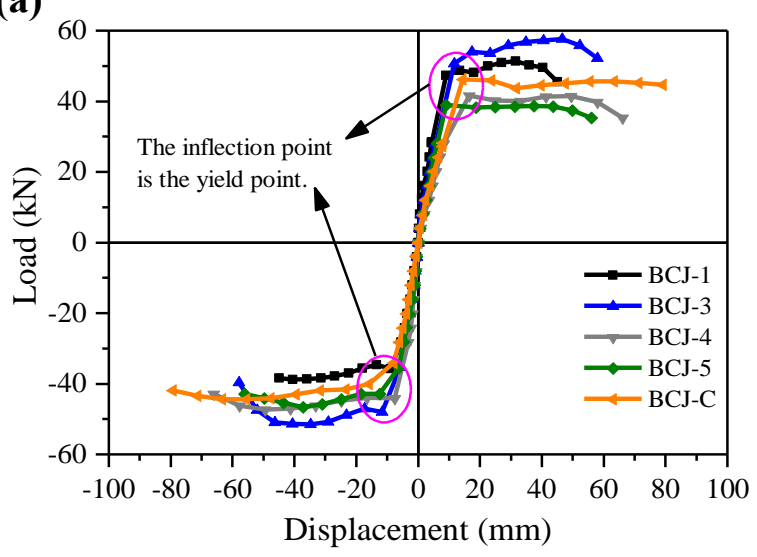

(b)

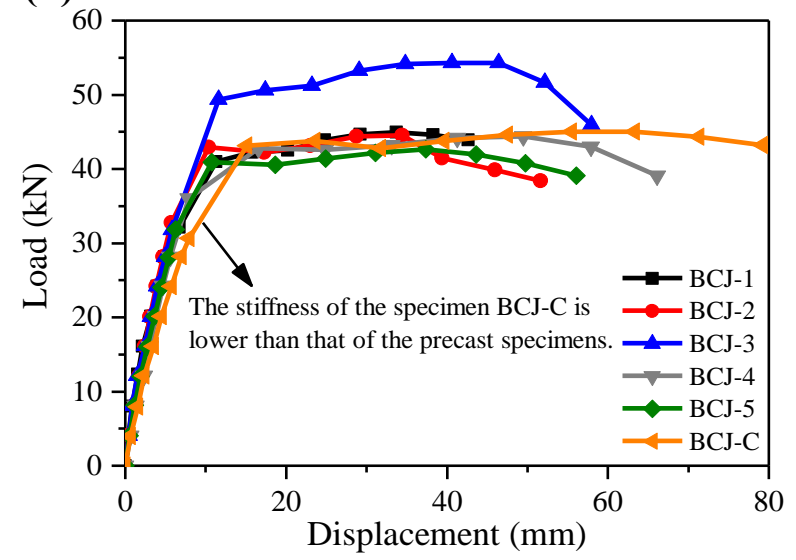

Fig. 19. Skeleton curves for cyclic loading specimens: (a) load-displacement envelope; (b) average load-displacement envelope.

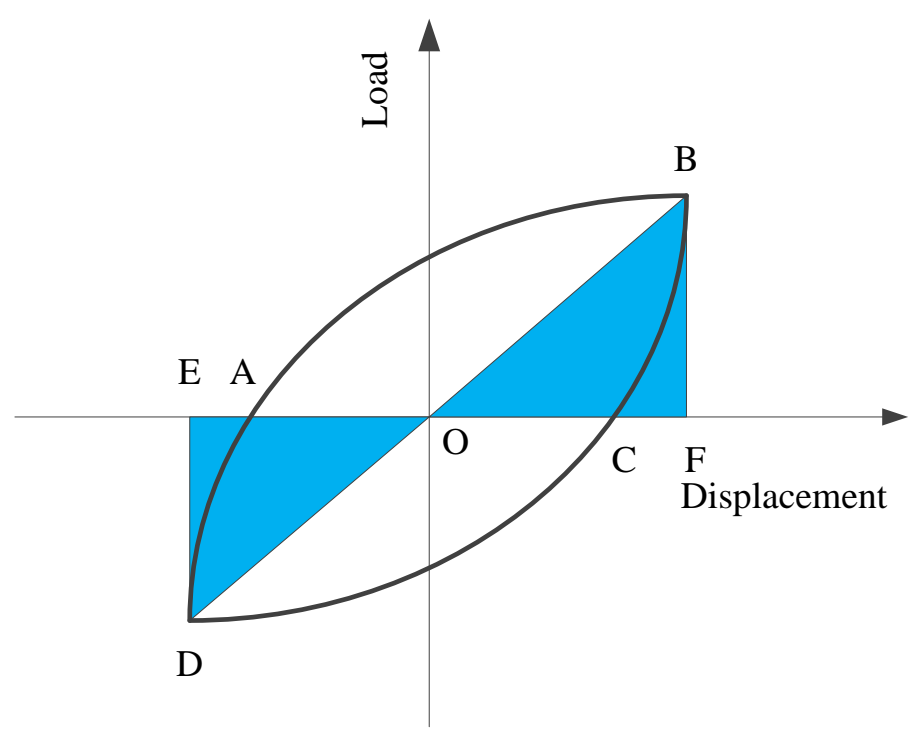

Fig. 20. Idealized hysteretic loop. 
(a)

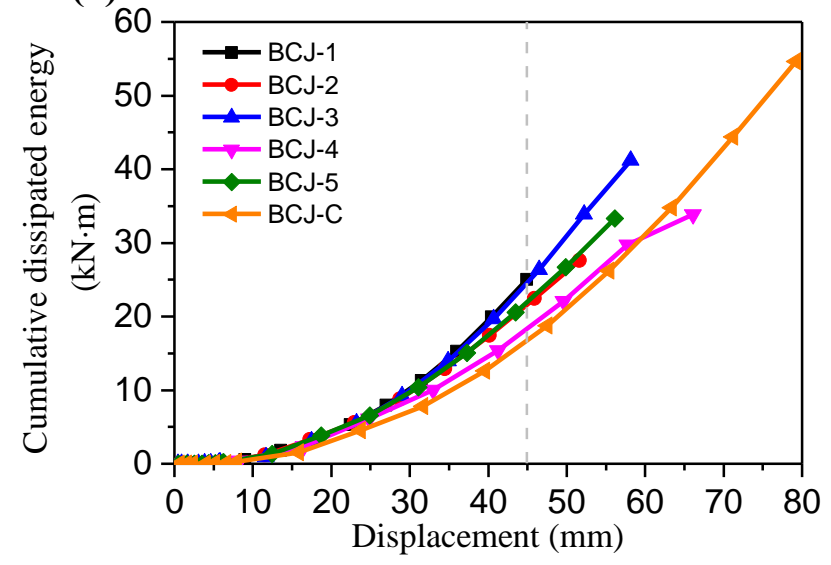

(b)

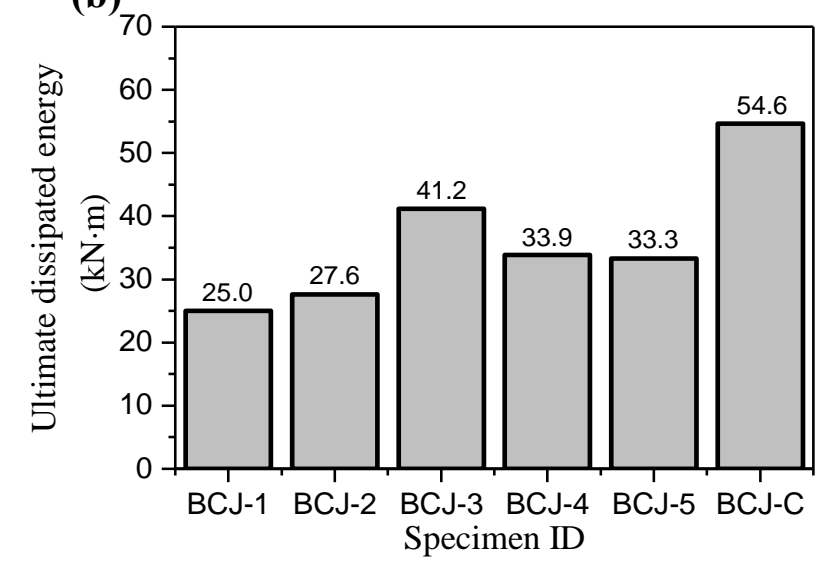

Fig. 21. Energy dissipation of specimens under cyclic loading: (a) evolution of cumulative dissipated energy; (b) ultimate dissipated energy.

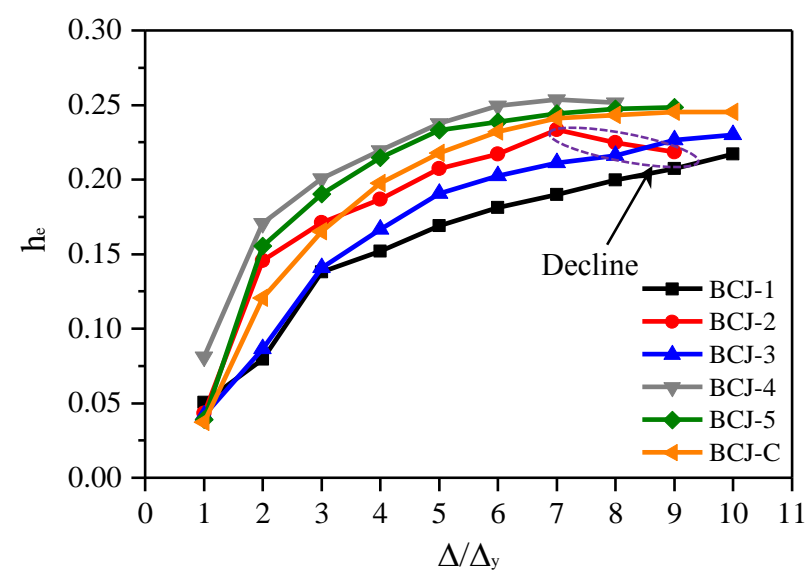

Fig. 22. Equivalent viscous damping coefficient for the specimens under cyclic loading.

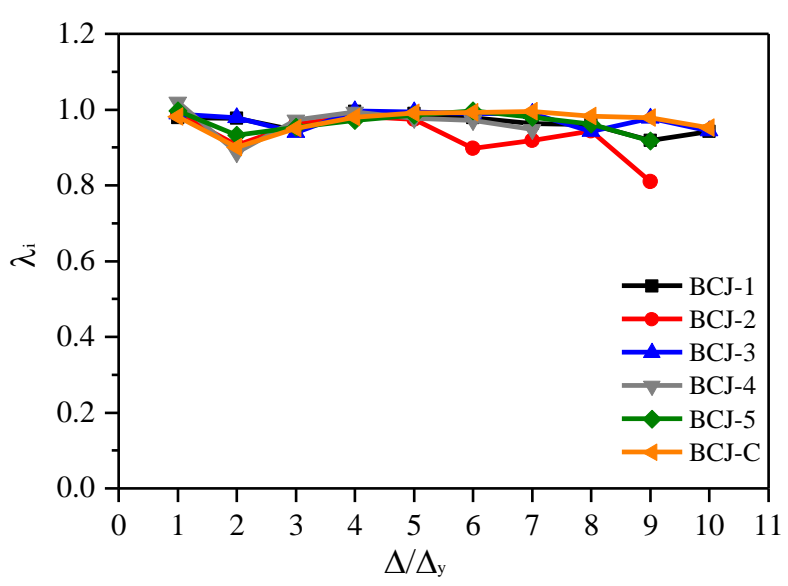

Fig. 23. Comparison of strength degradation. 
(a)

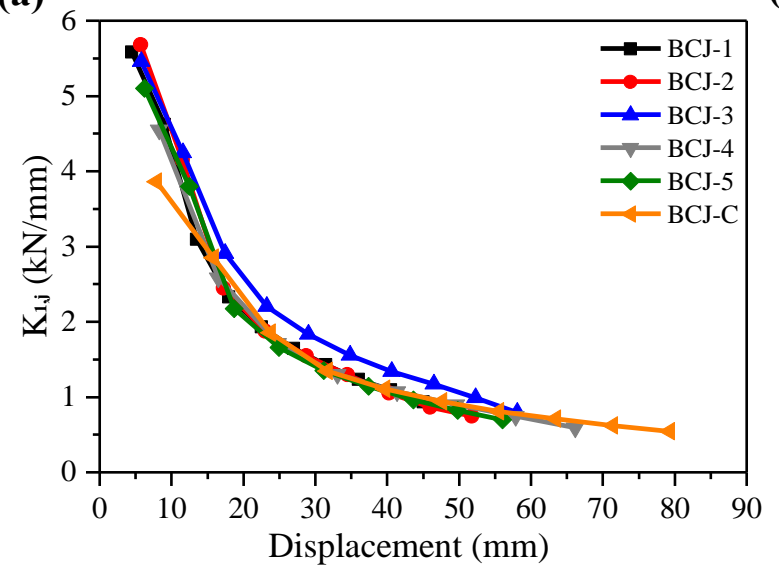

(b)

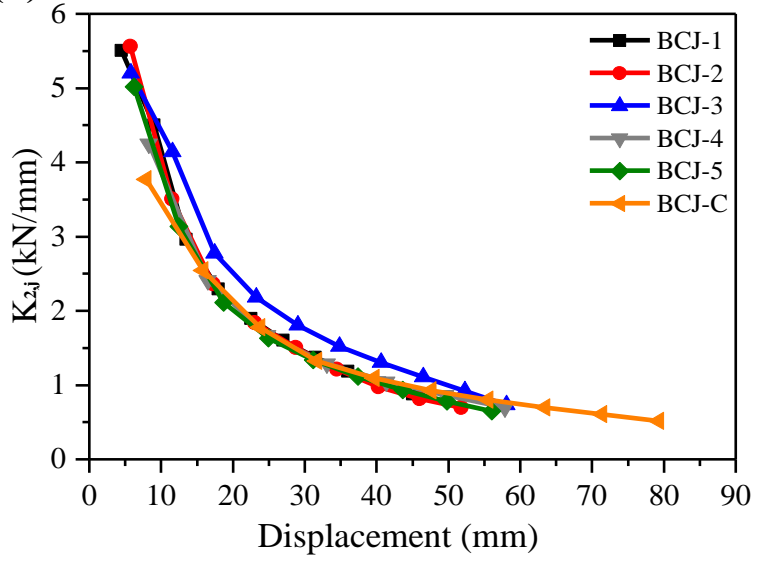

Fig. 24. Comparison of stiffness degradation: (a) first cycle; (b) second cycle.
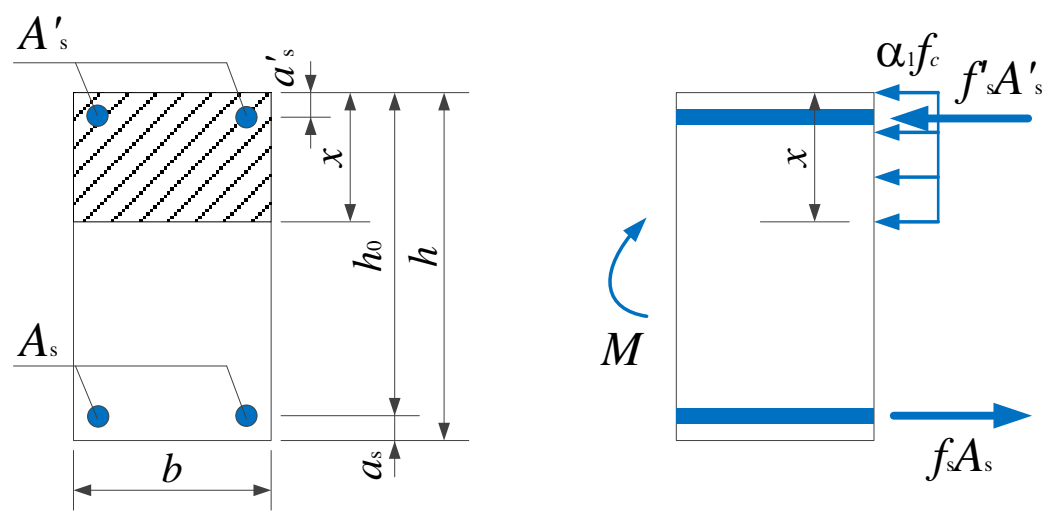

Fig. 25. Schematic diagram for calculating the flexural capacity of the beam. 
Tables

Table 1 Details of grouted sleeves

\begin{tabular}{cccccccc}
\hline $\begin{array}{c}\text { Name of } \\
\text { sleeve }\end{array}$ & $\begin{array}{c}\text { Types of } \\
\text { sleeve }\end{array}$ & $\begin{array}{c}\text { Types of } \\
\text { length }\end{array}$ & $L_{1}(\mathrm{~mm})$ & $L_{2}(\mathrm{~mm})$ & $L_{s}(\mathrm{~mm})$ & $D_{s}(\mathrm{~mm})$ & $t_{b}(\mathrm{~mm})$ \\
\hline GW-1 & GSW & Short & & $/$ & 275 & & \\
GW-2 & GSW & Long & 30 & $/$ & 400 & 42 & 5 \\
GT-1 & GSWT & Short & & 85 & 275 & & \\
GT-2 & GSWT & Long & & 85 & 400 & & \\
\hline
\end{tabular}

Note: $L_{1}$ is the wedge length; $L_{2}$ is the distribution length of thread; $L_{S}$ is the length of the grouted sleeve; $D_{s}$ is the outer diameter of the grouted sleeve and $t_{b}$ is the wall thickness of the grouted sleeve.

Table 2 Specimen design details

\begin{tabular}{cccccccccc}
\hline Specimen & $\begin{array}{c}\text { Column } \\
\text { size }(\mathrm{mm})\end{array}$ & $\begin{array}{c}\text { Beam size } \\
(\mathrm{mm})\end{array}$ & $\begin{array}{c}\text { Types of } \\
\text { specimen }\end{array}$ & $\begin{array}{c}\text { Short } \\
\text { sleeve }\end{array}$ & $\begin{array}{c}\text { Long } \\
\text { sleeve }\end{array}$ & $\begin{array}{c}\text { Types of } \\
\text { loading }\end{array}$ & $\begin{array}{c}d_{s} \\
(\mathrm{~mm})\end{array}$ & $\begin{array}{c}l_{a} \\
(\mathrm{~mm})\end{array}$ & $\mu$ \\
\hline BCJ-1 & & & Precast & GT-1 & GT-2 & Cyclic & 16 & 0 \\
BCJ-2 & & & Precast & GW-1 & GW-2 & Cyclic & 16 & 0 & \\
BCJ-3 & & & Precast & GT-1 & GT-2 & Cyclic & 18 & 0 & \\
BCJ-4 & \multirow{2}{*}{$350 \times 350$} & \multirow{2}{*}{$200 \times 350$} & Precast & GW-1 & GW-2 & Cyclic & 16 & 425 & 0.35 \\
BCJ-5 & & & Precast & GT-1 & GT-2 & Cyclic & 16 & 425 & \\
BCJ-S & & Precast & GT-1 & GT-2 & Static & 16 & 425 & \\
BCJ-C & & & Monolithic & $/$ & $/$ & Cyclic & $/$ & $/$ & \\
\hline
\end{tabular}

Note: $d_{s}$ is the diameter of the transition bar; $l_{a}$ is the assembly length (i.e. the length of protruding beam of precast column) of the joint and $\mu$ is the axial compression ratio of column.

Table 3 Material properties of steel bars

\begin{tabular}{cccccc}
\hline $\begin{array}{c}\text { Type of } \\
\text { reinforcement }\end{array}$ & Grade & Diameter $(\mathrm{mm})$ & $f_{y}(\mathrm{MPa})$ & $f_{u}(\mathrm{MPa})$ & $E(\mathrm{GPa})$ \\
\hline $\begin{array}{c}\text { Stirrup } \\
\text { Longitudinal bar }\end{array}$ & HRB400 & 8 & 431 & 580 & 200 \\
Transition bar $A$ & HRB400 & 16 & 428 & 569 & 198 \\
Transition bar $B$ & HRB400 & 16 & 418 & 556 & 198 \\
\hline
\end{tabular}

Note: $f_{y}$ is the yield strength of reinforcement; $f_{u}$ is the tensile strength of the reinforcement and $E$ is the elastic modulus.

Table 4 Material properties of concrete, grout and filler

\begin{tabular}{cccc}
\hline Specimen & $\begin{array}{c}\text { Compressive strength } \\
(\mathrm{MPa})\end{array}$ & $\begin{array}{c}\text { Flexural strength } \\
(\mathrm{MPa})\end{array}$ & Water-material ratio \\
\hline Concrete & 39.8 & $/$ & $/$ \\
Grout & 86.2 & 14.5 & 0.13 \\
Filler & 82.1 & 13.9 & 0.12 \\
\hline
\end{tabular}


Table 5 Statistics of test results

\begin{tabular}{|c|c|c|c|c|c|c|c|c|c|c|c|c|c|c|c|c|c|}
\hline \multirow[t]{2}{*}{ Specimen } & \multicolumn{2}{|c|}{$P_{y}(\mathrm{kN})$} & \multirow[t]{2}{*}{$\overline{P_{y}}$} & \multicolumn{2}{|c|}{$\Delta_{y}(\mathrm{~mm})$} & \multicolumn{2}{|c|}{$P_{\max }(\mathrm{kN})$} & \multirow[t]{2}{*}{$\bar{P}_{\max }$} & \multicolumn{2}{|c|}{$\Delta_{\max }(\mathrm{mm})$} & \multicolumn{2}{|c|}{$P_{u}(\mathrm{kN})$} & \multicolumn{2}{|c|}{$\Delta_{u}(\mathrm{~mm})$} & \multicolumn{2}{|l|}{$\mu_{\Delta}$} & \multirow[t]{2}{*}{$\bar{\mu}$} \\
\hline & $(+)$ & $(-)$ & & $(+)$ & $(-)$ & $(+)$ & $(-)$ & & $(+)$ & $(-)$ & $(+)$ & $(-)$ & $(+)$ & $(-)$ & $(+)$ & $(-)$ & \\
\hline BCJ-1 & 47.34 & -35.77 & 41.56 & 9.02 & -8.96 & 51.31 & -38.88 & 45.10 & 31.49 & -40.51 & 45.49 & -38.38 & 44.99 & -44.91 & 4.99 & 5.01 & 5.00 \\
\hline BCJ-2 & 40.20 & -45.64 & 42.92 & 9.38 & -11.32 & 40.20 & -50.50 & 45.35 & 9.38 & -40.23 & 26.84 & -49.91 & 51.63 & -51.71 & 5.50 & 4.57 & 5.04 \\
\hline BCJ-3 & 50.68 & -47.95 & 49.32 & 11.65 & -11.58 & 57.63 & -51.47 & 54.55 & 46.47 & -34.88 & 52.13 & -39.72 & 57.98 & -58.00 & 4.98 & 5.01 & 5.00 \\
\hline BCJ-4 & 41.62 & -44.07 & 42.85 & 16.56 & -7.54 & 41.62 & -47.33 & 44.48 & 16.56 & -49.47 & 35.37 & -42.81 & 66.12 & -66.14 & 3.99 & 8.77 & 6.38 \\
\hline BCJ-5 & 38.97 & -42.86 & 40.92 & 9.09 & -12.46 & 38.97 & -46.57 & 42.77 & 9.09 & -37.32 & 35.31 & -42.90 & 56.03 & -56.12 & 6.16 & 4.50 & 5.33 \\
\hline BCJ-C & 46.18 & -40.06 & 43.12 & 14.35 & -15.89 & 46.18 & -44.41 & 45.30 & 14.35 & -55.44 & 44.63 & -41.82 & 79.19 & -79.30 & 5.52 & 4.99 & 5.26 \\
\hline
\end{tabular}

Note: $(+)$ and $(-)$ indicate the positive (pushing) and negative (pulling) loading directions, respectively; $P_{y}$ is the yield load and $\Delta_{y}$ is the corresponding displacement; $\bar{P}_{y}$ is average yield load in the positive and negative directions of loading; $P_{\max }$ is the maximum load and $\Delta_{\max }$ is the corresponding displacement; $\bar{P}_{\text {max }}$ is the average maximum load in the positive and negative directions of loading; $P_{u}$ is the failure load and $\Delta_{u}$ is the corresponding displacement; $\mu_{\Delta}$ is the displacement ductility coefficient and $\bar{\mu}$ is the average displacement ductility coefficient in the positive and negative directions of loading.

Table 6 Comparison between predictions and experimental results of flexural capacity

\begin{tabular}{cccccccc}
\hline Specimen & BCJ-S & BCJ-1 & BCJ-2 & BCJ-3 & BCJ-4 & BCJ-5 & BCJ-C \\
\hline$M_{\text {exp }}(\mathrm{kN} \cdot \mathrm{m})$ & 57.98 & 58.63 & 58.96 & 70.92 & 57.82 & 55.60 & 58.89 \\
$M_{\text {pre }}(\mathrm{kN} \cdot \mathrm{m})$ & 59.03 & 57.68 & 57.68 & 72.83 & 59.03 & 59.03 & 59.03 \\
Error $(\%)$ & 1.78 & -1.65 & -2.22 & 2.62 & 2.05 & 5.81 & 0.24 \\
\hline
\end{tabular}

